\title{
EARLY \\ IMPACTS OF COLLEGE AID
}

Cáceres-Delpiano, Julio 


\title{
EARLY IMPACTS OF COLLEGE AID
}

\author{
Cáceres-Delpiano, Julio \\ Giolito, Eugenio \\ Castillo, Sebastián \\ CAF - Working paper $N^{\circ} 2015 / 06$ \\ $28 / 07 / 2015$
}

\begin{abstract}
We analyze the impact of an expansion in government-guaranteed credit for higher education in Chile on a sample of elementary and high school students. Using students who had an alternative source of funding as a control group, and administrative records before and after the reform, we present evidence that students most likely to attend college in a future are affected in different ways. First, we show that parents of students who ex ante were more likely to be credit restricted became more likely after the reform to state that their child would end up completing college. Second, we find that relaxing credit restrictions reduces the probability of dropping out of high school, specific among top students originally enrolled in low-performance schools and low-performance students attending better schools. Third, we find that the reform led to an increase in educational sorting. Best students switch to better schools while lowperformance students go to lower-ranked schools. This sorting helps to explain why we observe a decrease (increase) in GPA and an increase (decrease) in grade repetition among better (worse) students. Then, for a sample of students that were in transition from elementary to secondary school, we show that good students are more likely to enroll in a college-oriented track. Finally, using household data and birth records aggregated at the municipal level, we find, consistent with previous findings, a reduction in teen pregnancy.
\end{abstract}

Small sections of text, that are less than two paragraphs, may be quoted without explicit permission as long as this document is stated. Findings, interpretations and conclusions expressed in this publication are the sole responsibility of its author(s), and it cannot be, in any way, attributed to CAF, its Executive Directors or the countries they represent. CAF does not guarantee the accuracy of the data included in this publication and is not, in any way, responsible for any consequences resulting from its use. 


\section{IMPACTO TEMPRANO DE LAS AYUDAS FINANCIERAS PARA ESTUDIOS SUPERIORES \\ Cáceres-Delpiano, Julio \\ Giolito, Eugenio \\ Castillo, Sebastián \\ CAF - Documento de trabajo No 2015/06 \\ $28 / 07 / 2015$}

RESUMEN

En este trabajo analizamos el impacto de la expansión del Crédito con Aval del Estado para la educación superior en Chile en una muestra de estudiantes de escuelas primarias y secundarias. Utilizando a los estudiantes que tenían una fuente alternativa de financiación como grupo de control, así como los registros administrativos antes y después de la reforma, presentamos evidencia de que los estudiantes con más probabilidades de asistir a la universidad en un futuro se ven afectados de diferentes maneras. En primer lugar, encontramos que los padres de los estudiantes que a priori eran más propensos a tener restricciones al crédito son más propensos, luego de la reforma, de afirmar que su hijo terminará la universidad. En segundo lugar, encontramos que la existencia del programa reduce la probabilidad de abandonar la escuela secundaria, específicamente entre los mejores alumnos inicialmente matriculados en las escuelas de bajo rendimiento y los estudiantes de bajo rendimiento que asisten a mejores escuelas. En tercer lugar, encontramos que la reforma dio lugar a un aumento en el cambio de colegios. Mientras que los mejores estudiantes se cambiaron a mejores escuelas, los estudiantes de bajo rendimiento fueron a peores establecimientos. Esto ayuda a explicar por qué se observa una disminución (aumento) de GPA y un aumento (disminución) de repitencia entre los mejores (peores) estudiantes. Luego, para una muestra de estudiantes que estaban en transición de la primaria a la escuela secundaria, se muestra que los buenos estudiantes son más propensos a elegir en el secundario las ramas educativas enfocadas en la preparación para la universidad. Por último, el uso de datos de los hogares y los registros de nacimiento agregados a nivel municipal, encontramos, en consonancia con los resultados anteriores, una reducción de los embarazos de adolescentes.

\footnotetext{
Small sections of text, that are less than two paragraphs, may be quoted without explicit permission as long as this document is stated. Findings, interpretations and conclusions expressed in this publication are the sole responsibility of its author(s), and it cannot be, in any way, attributed to CAF, its Executive Directors or the countries they represent. CAF does not guarantee the accuracy of the data included in this publication and is not, in any way, responsible for any consequences resulting from its use.
} 


\title{
Early Impacts of College Aid*
}

\author{
Julio Cáceres-Delpiano ${ }^{\dagger} \quad$ Eugenio Giolito ${ }^{\ddagger} \quad$ Sebastián Castillo ${ }^{\S}$
}

July 28, 2015

\begin{abstract}
We analyze the impact of an expansion in government-guaranteed credit for higher education in Chile on a sample of elementary and high school students. Using students who had an alternative source of funding as a control group, and administrative records before and after the reform, we present evidence that students most likely to attend college in a future are affected in different ways. First, we show that parents of students who ex ante were more likely to be credit restricted became more likely after the reform to state that their child would end up completing college. Second, we find that relaxing credit restrictions reduces the probability of dropping out of high school, specifically among top students originally enrolled in low-performance schools and low-performance students attending better schools. Third, we find that the reform led to an increase in educational sorting. Best students switch to better schools while low-performance students go to lower-ranked schools. This sorting helps to explain why we observe a decrease (increase) in GPA and an increase (decrease) in grade repetition among better (worse) students. Then, for a sample of students that were in transition from elementary to secondary school, we show that good students are more likely to enroll in a college-oriented track. Finally, using household data and birth records aggregated at the municipal level, we find, consistent with previous findings, a reduction in teen pregnancy.
\end{abstract}

Keywords: high school dropouts, college credit, teen pregnancy.

JEL classification: I28, J13

*We want to thank the participants at the workshop "Capital Humano y Habilidades para la Vida y el Trabajo" (Buenos Aires, Argentina, 21-22 of July 2015), and seminar participants at the Departments of Economics at Universidad Carlos III and Pontificia Universidad Catolica de Chile for comments and suggestions. Financial support from Fondecyt (Grant 1130565) and from Corporación Andina de Fomento is gratefully acknowledged. Julio Cáceres-Delpiano gratefully acknowledges financial support from the Spanish Ministry of Education (Grant ECO2009-11165). We thank MINEDUC and Agencia de Calidad de la Educación (Chile) for the access to the data used in this paper. Errors are ours.

$\dagger$ Universidad Carlos III de Madrid. E-mail: jcaceres@eco.uc3m.es

†LADES/ Universidad Alberto Hurtado and IZA. E-mail: egiolito@uahurtado.cl

$\S$ Universidad Miguel de Cervantes. E-mail: scastillo@umcervantes.cl 


\section{Introduction}

In this paper we analyze the impact of a major expansion in college aid on a sample of primary and secondary school students in Chile. Specifically, the policy consisted in government-guaranteed university loans (Crédito con Aval del Estado, hereafter CAE), implemented in 2006. Over the span of five years after the reform, $30 \%$ of all college students were receiving aid through this program. Given the magnitude of the reform, the main hypothesis of this paper is that CAE not only lifted credit restrictions for students who were planning to attend college but also enhanced expectations about higher education among students, who at the time were in primary and secondary education. In other words, we would expect a change in the behavior of those students well before they applied to college.

Before the CAE reform, most of the funds for student aid were concentrated on individuals attending a subset of "traditional" institutions. These schools were historically able to impose a higher entry cutoff in the national standardized admission test. This means that, by expanding college aid to all higher education institutes, the reform was perceived as a relaxation in the academic requirements to obtain student aid. To evaluate the policy, we use the fact that given the high level of socioeconomic segregation in the Chilean educational system, the best students in better ranked schools had an alternative source of funding before and after the intervention. Therefore, using school records for Chilean elementary and high school students, which allow us to rank them both by their own performance and by that of their school's before the reform, we can identify them as our control group.

In the following sections, we present evidence that students at the margin of attending college in the future are affected in different ways. First, we show that parents of students who were more likely to be credit restricted before the reform, are more likely to report after the implementation of CAE that the student in the future will complete college education. Second, we find that lifting future credit restrictions reduces the probability 
of dropping out of high school. Specifically, we find that the decrease in the dropout rates is concentrated among the best students in lower-ranked schools and low-achieving students in higher-ranked schools. Third, we find that the reform led to an increase in educational sorting, with the best students switching to a school of better quality and under-performing students to lower-ranked schools. Both previous results help to explain why we observe a decrease (increase) in GPA and an increase (decrease) in grade repetition among better (worse) students. Then, we analyze a sample of students that, at the time of the reform, were in transition from elementary to secondary school, finding that good students are more likely to enroll in a college-oriented track (scientific-humanistic). While the results on school switching are similar to those for the sample of students already in high school, the results for school performance have, however, the opposite sign. Finally, using household data and age specific birth rates aggregated at the municipal level, we find, consistent with previous findings, a reduction in teen pregnancy.

Our paper is related to several strands of the literature. The first one consists of studies stressing the role of credit restrictions on college enrollment decisions. Given the relative importance of post-secondary education in the system, the evidence provided has focused on developed countries (see, for example Stinebrickner and Stinebrickner, 2008 and Lochner and Monge-Naranjo, 2011). In the same line of research, a handful of studies have specifically evaluated the impact of the CAE reform. Rau et al. (2013) show that the CAE reform had not only increased enrollment rates in post-secondary education but had also reduced dropout rates at the college level 11 Solis (2012), using a discontinuity in the assignment rule to the CAE (and other college aid alternatives), finds a significant positive effect on enrollment and a negative effect on college dropout rates. Both studies, however, (Rau et al., 2013 and Solis, 2012), focus on the margin of students attending college and post secondary outcomes, different from this paper.

A second line of research studies the role of expectations (and their interaction with

\footnotetext{
${ }^{1}$ Nevertheless, Rau et al. (2013) show that CAE's beneficiaries do not have higher earnings, because of perverse incentives introduced by the reform into post secondary institutions.
} 
credit restrictions) on human capital accumulation [2 (see, for example, Jacob and Wilder, 2011 for the U.S. and Attanasio and Kaufmann, 2009 for Mexico ${ }^{3}$. Specifically for Chile, Dinkelman and Martinez (2013) perform a randomized controlled experiment among eighth graders, where treated students were informed about credit and fellowships opportunities. The results reveal that the exposure to information increases college-oriented high school enrollment (scientific-humanistic), primary school attendance, and financial aid knowledge, with gains concentrated among medium- and high-grade students. Given that in this paper we analyze the impact of the actual expansion of college credit, rather than information about the policy itself, our results on the choice of the academic track are consistent with the findings of Dinkelman and Martinez (2013) in a controlled setting.

The final strand of the literature to which this paper relates, is the one studying the role of lifting restrictions to higher education on the (signal) value associated to a specific education level. Bedard (2001) finds, for the U.S., that regions with easier access to college are characterized by higher dropout rates. The previous result is explained in a model where education has a signaling value. Starting from an equilibrium where students are constrained in accessing higher education (and thus both high and low ability students are "pooled" in high school graduation), a reduction in those barriers leads some high ability students to continuing with their education beyond high school. This deviation of high ability students, on the other hand, reduces the value of education for less able students for whom originally completing high school was optimal, but who in this new equilibrium, become high school dropouts. Given that we analyze a policy that was aimed directly at reducing barriers to entering college, and that we do have a measure of academic ability

\footnotetext{
${ }^{2}$ There is growing literature stressing the importance of subjective expectations in economics beyond the ones associated to the return of education. For a revision of this literature, see Attanasio and Kaufmann (2009) and Attanasio (2009).

$\sqrt[3]{J a c o b}$ and Wilder, 2011 analyze trends in educational expectations between the mid-1970s and the early 2000s, finding that, even though expectations have become somewhat less predictive of attainment, they do remain strong predictors of attainment above and beyond other standard determinants of schooling.

${ }_{4}^{4}$ Attanasio and Kaufmann (2009), using household data for Mexico, show a positive correlation between individual's expectations about the return of education and educational decisions, even though this correlation is weaker among individuals who are more likely to be credit constrained.
} 
previous to the reform, we find ourselves with an adequate environment for evaluating the signaling hypothesis in a context of a strong school's heterogeneity, rather than differences in the local supply of universities as in Bedard (2001).5 Specifically, we find that, for schools with a relatively high dropout rate (and low average score in standardized tests), the reform caused some of the high ability students to be less likely to drop out and therefore to separate from their low-ranked peers, which is consistent with Bedard's results. However, in schools with a low average dropout rate (high average score), the dropout rate falls for students at the bottom of the distribution, who are more likely to join their highperformance classmates in pursuing a college degree. Both results are consistent with a low value of the high school graduation as a signal, other than being a prerequisite for higher education. We also find that this separation between high and low ability students starts as early as ninth grade, when they choose the academic track that prepares them better for college admission.

The paper is organized as follows. In Section 2, we briefly describe the main aspects of the Chilean educational system, as well as the main features of the CAE. In Section 3, we describe our empirical strategy. Section 4 presents the data, samples and outcomes used in the analysis. In Section 5 we present our results. Section 6 concludes.

\footnotetext{
${ }^{5}$ Moreover, we may be able to provide an estimate that is less likely to be contaminated by spillovers in education. Moretti (2004) finds that an increase in the supply of college graduates raises high school drop-outs' wages by almost five times the increase in college graduates wages.
} 


\section{The CAE reform and the education system in Chile}

Since a major educational reform in the early 1980 6 Chile's primary and secondary educational system has been characterized by its decentralization and by a significant participation of the private sector. By the year 2012, the population of students was approximately three and half million, distributed throughout three types of schools: public or municipal (41\% of total enrollment), subsidized private (51\% of total enrollment), and non-subsidized private schools $(7 \%$ of total enrollment) 7 . Municipal schools, as the name indicates, are managed by municipalities, while the other two types of schools are controlled by the private sector. Though both municipal and subsidized private schools get state funding through a voucher scheme, the latter are usually called "voucher schools" 8

Primary education consists of eight years of education while secondary education depends on the academic track followed by a student. A "Scientific-Humanist" track consists of four years and it prepares students for a college education. A "Technical-Professional" track has a duration in some cases of five years, with a vocational orientation aiming to help the transition into the workforce after secondary education. Until 2003, compulsory education consisted of eight years of primary education; however, a constitutional reform established free and compulsory secondary education for all Chilean inhabitants up to the age of eighteen. Despite mixed evidence on the impact of a series of reforms introduced as

\footnotetext{
${ }^{6}$ The management of primary and secondary education was transferred to municipalities, payment scales and civil servant protection for teachers were abolished, and a voucher scheme was established as the funding mechanism for municipal and non- fee-charging private schools. Both municipal and nonfee-charging private schools received equal rates tied strictly to attendance, and parents' choices were not restricted to residence. Although with the return to democracy some of the earlier reforms have been abolished or offset by new reforms (policies), the Chilean primary and secondary educational system is still considered one of the few examples in a developing country of a national voucher system, which in the year 2009 covered approximately $93 \%$ of the primary and secondary enrollment. For more details, see Gauri and Vawda (2003).

'There is a fourth type of schools, "corporations", which are vocational schools administered by firms or enterprises with a fixed budget from the state. In 2012, they constituted less than $2 \%$ of the total enrollment. Throughout our analysis, we treat them as municipal schools.

${ }^{8}$ Public and "voucher" schools are allowed to receive a copayment from parents, even though the latter have fewer restrictions in their copayment policy. According to Gallego and Hernando (2008), 78 percent of municipal school students attend free schools (that is, schools that do not require a copayment in addition to the voucher), while only 24 percent of voucher school students attend free voucher schools.
} 
of the early 1980's on the quality of education, Chile's primary and secondary education systems are comparable in terms of coverage to those in any developed country 9

The tertiary education is provided by three types of higher education institutions (HEI): Universities, Professional Institutes (PI) and Technical Institutes (TI) ${ }^{10}$. Among colleges, we are able to distinguish those created before the year 1981 (often called "traditional"), which belong to the Consejo de Rectores de las Universidades Chilenas (CRUCh) from those created later on 12

Although all students planning to go on to post-secondary education need high school certification, the specific requirements depend on the particular institution they are planning to attend. On the one hand, to be admitted by most universities, students at the end of high school must take the national standardized college admission test (PSU, Prueba de Selección Universitarid ${ }^{13}$. The final application score is a weighted average of the score associated to the high school grade average and the final PSU score ${ }^{14}$, Requirements in TI and PI institutions, on the other hand, are often reduced to a minimum GPA in high school.

\footnotetext{
${ }^{9}$ The bulk of research has focused on the impact of the voucher-funding reform on educational achievements. For example, Hsieh and Urquiola (2006) find no evidence that school choice improved average educational outcomes as measured by test scores, repetition rates, and years of schooling. Moreover, they find evidence that the voucher reform was associated to an increase in sorting. Other papers have studied the extension of school days on children outcomes (Berthelon and Kruger, 2011), teacher incentives (Contreras and Rau, 2012) and the role of information about the school's value added on school choice (Mizala and Urquiola | 2013), among other reforms. For a review of these and other reforms since the early 1980's, see Contreras et al. (2005).

${ }^{10}$ The TI are institutions that are allowed to grant technical degrees (2 or 3 years of coursework) and PI are permitted to grant technical and professional degrees, but not bachelor degrees.

${ }^{11}$ This group includes 25 public and private schools that were already in the system by 1981 .

${ }^{12}$ The schools created after 1981 are commonly called "private" as they do not receive direct government subsidies, as "traditional" schools do.

${ }^{13}$ The 25 universities belonging to the Consejo de Rectores, plus 8 "private" universities, participate in a centralized admission system, coordinated by the Universidad de Chile, which every year determines the weight of PSU and high school GPA. Since 2013 they also consider the student's ranking in their class in addition to GPA.

${ }^{14}$ The final PSU is a weighted average of core topics and other specific topics required by the program/institution that a student will apply to. There is an important debate currently going on in Chile about the contents of the PSU test. Critics argue that, PSU being a test measuring knowledge of the scientific-humanistic high school curriculum, instead of aptitude, favors students from higher socioeconomic backgrounds going to elite private (non-subsidized) high schools.
} 


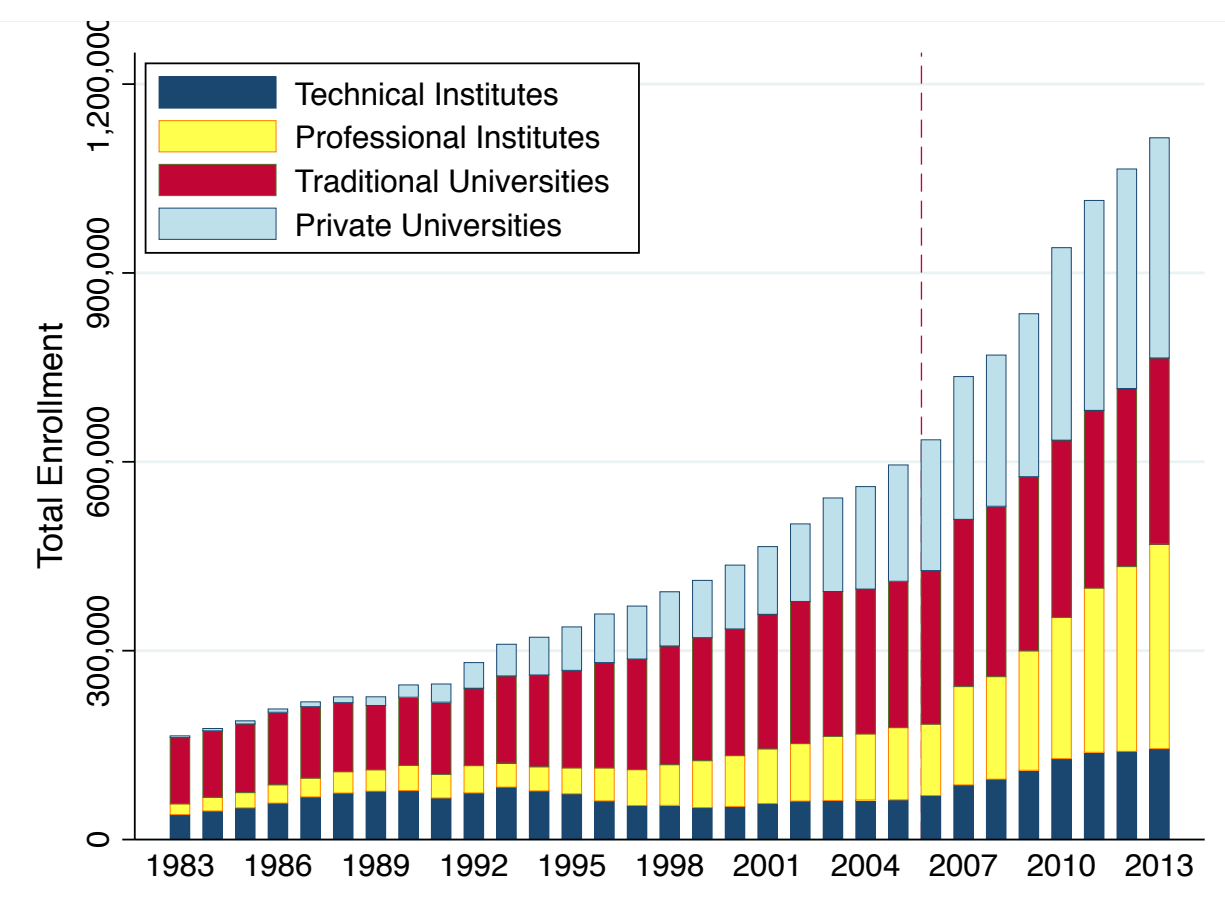

Figure 1: Enrollment in HEI, 1983-2013. Source: SIES/Mineduc

From the early 1980s to the mid 2000s, and particularly during the 1990s, total enrollment in HEIs in Chile increased sharply, as shown in Figure 1. This increase occurred along with the creation of a large number of private (non-traditional) universities, PI and TI. Despite this expansion in the supply, college tuitions relative to average income are still one of the highest in the world 15 That is, one of the first goals of the CAE reform was to increase the affordability of post-secondary education.

However, before the CAE reform in 2006, there was another source of governmentguaranteed credit for higher education, the $F S C U{ }^{16}$ This credit, however, was only available to students attending one of the "traditional" colleges which, due to their better reputation, were overrepresented by students coming from wealthier families. These students were able to attend the best secondary schools and outperform others from middle and low-income families in the national standardized college admission test. The high

\footnotetext{
${ }^{15}$ Figure 12 in the Appendix shows university tuition fees in Chile compared with other OECD countries. Note that, different from other countries, in Chile tuition fees are similar for public and private universities.

${ }^{16}$ The Fondo Solidario de Crédito Universitario (FSCU) is a benefit existing since 1981.
} 


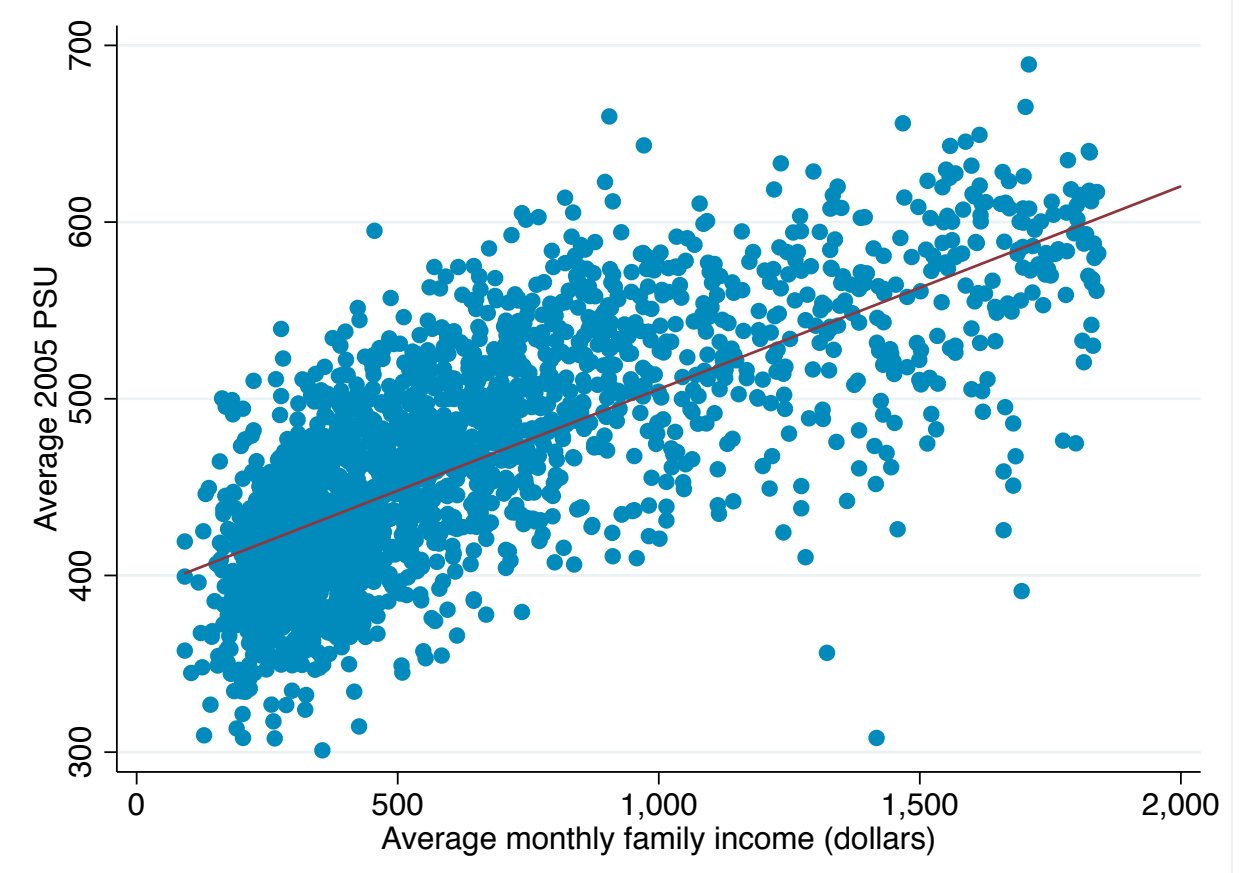

Figure 2: Average Family Income and PSU Score by School

correlation between average PSU scores (at the school level) and family income becomes clear when looking at Figure $2{ }^{17}$

Given the restrictions in access to credit and differences in the quality of high schools, an important proportion of students in new private universities come from middle or low income families. In order to balance out these differences in access to credit for higher education, the government started to increase the amount of resources devoted to student aid and loans, as shown in Figure 3. Notice that this increase in student aid closely follows the rise in enrollment observed since 2006, particularly in PI and the new "private" universities, the two main types of HEI CAE beneficiaries, as shown in Figure $4{ }^{18}$

\footnotetext{
${ }^{17}$ Mizala et al. (2007) show that, in the case of Chile, a ranking of schools based on standardized tests scores is very similar to rankings based purely on students' socioeconomic status.

${ }^{18}$ Despite the fact that the expansion in scholarships was also aimed at middle and low-income students, they were mostly not targetting students in the new "private" universities. The two most numerous scholarships were the "Beca Bicentenario", for students enrolled in one of the 25 "traditional" universities, and the "Beca Nuevo Milenio", for students pursuing "professional" careers in PI.
} 


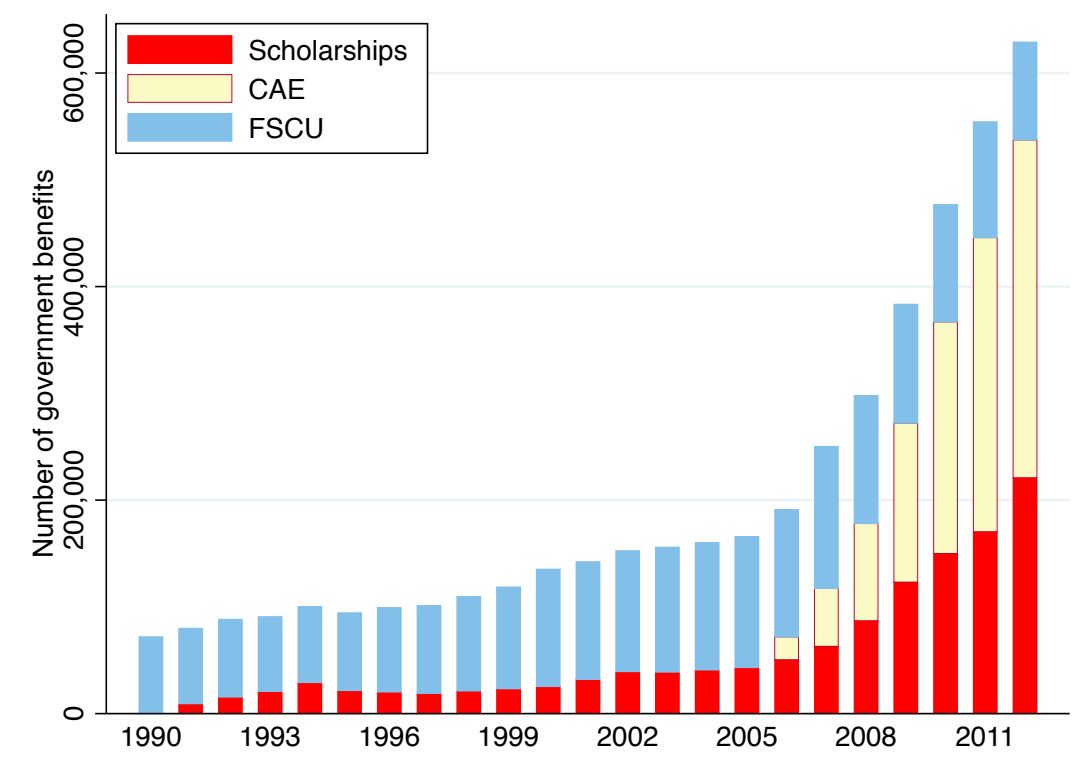

Figure 3: Government student aid, 1990-2012. Source: SIES/Mineduc
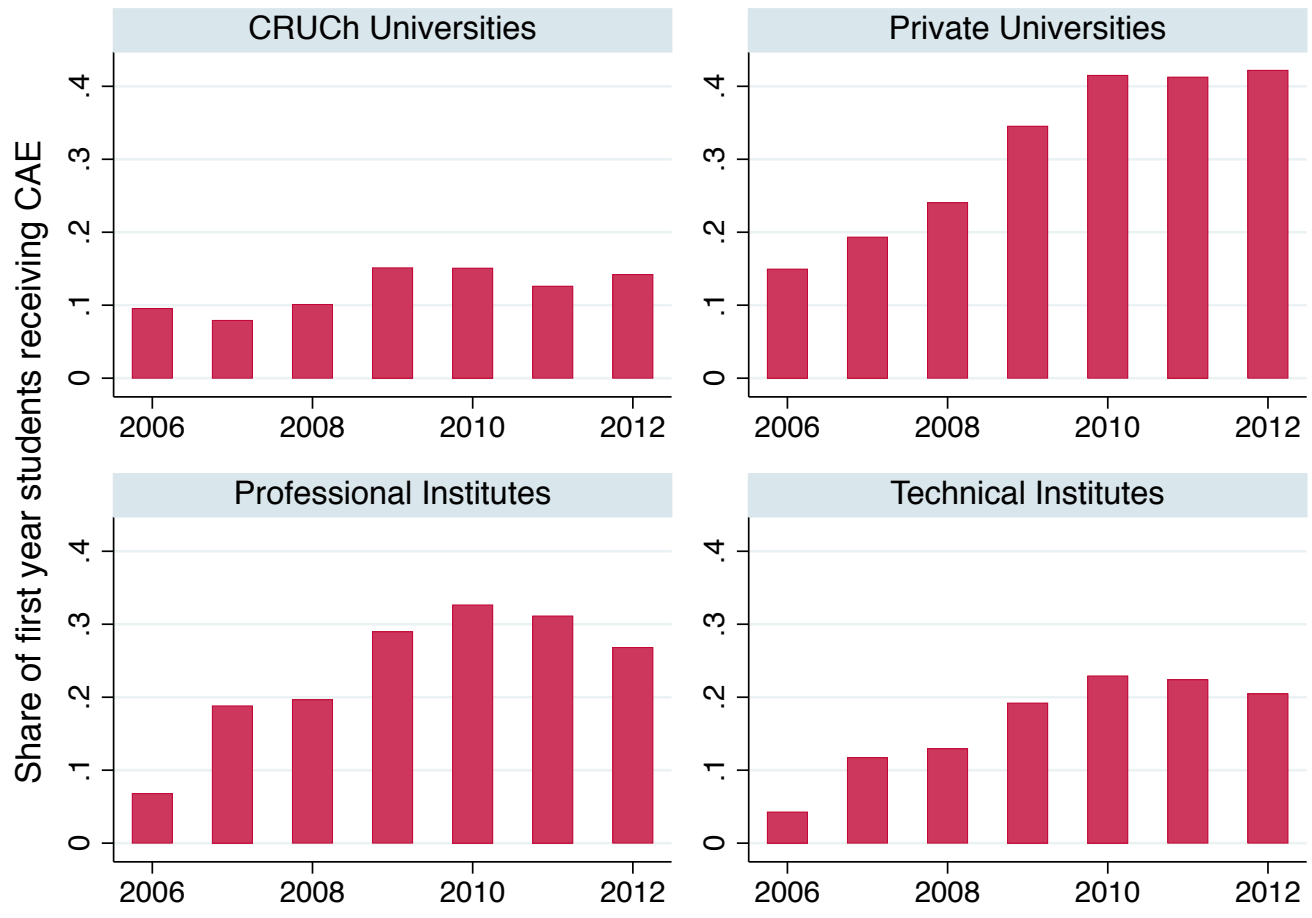

Figure 4: Share of first year students receiving CAE, by type of HEI. Source: Comisión Ingresa/Mineduc

Among this new student aid, CAE has become the most important source of funding. 


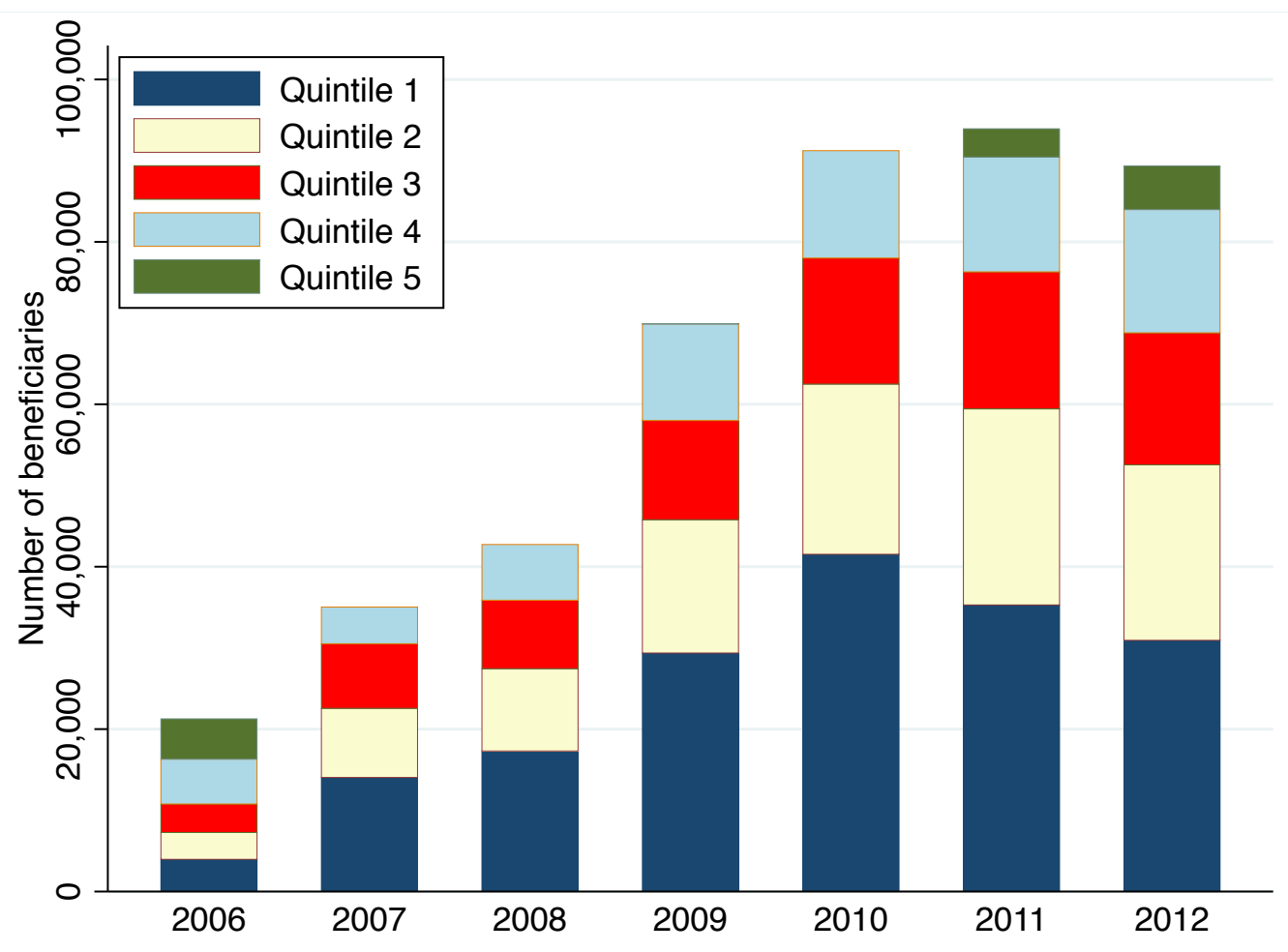

Figure 5: Number of new CAE beneficiaries, by quintile of income. Source: SIES/Mineduc

Established in 2006 ${ }^{19}$ it consists of a government guaranteed loan granted by private financial institutions to students enrolled in an accredited HEI. The targeted population is students with financial difficulties who wish to enter or continue their studies in a higher education institution. As shown in Figure 5, CAE has not only been a success in terms of coverage but also in terms of the targeted population ${ }^{20}$ That is, the number of CAE beneficiaries for the period 2006-2012, was concentrated among students in the first two quintiles of the income distribution.21

In order to ensure eligibility for the $\mathrm{CAE}$, a student has to obtain at least 475 points in the PSU if she/he was admitted at a certified university, or to reach a minimum GPA in

\footnotetext{
${ }^{19}$ This benefit was established by Law No. 20,027 of 2005, with its application beginning the following year.

${ }^{20}$ Using Chile's population survey (CASEN), Figure 5 in the Appendix shows that the share of college students in the three lowest quintiles of the income distribution has risen sharply since the introduction of CAE in 2006.

${ }^{21}$ Note in Figure 5 that in 2006 the assignment of credits was similar for the five quintiles because of an administrative mistake by the officials who determined the beneficiaries (they originally ranked the priorities in inverted order, from the richest quintile to the poorest).
} 


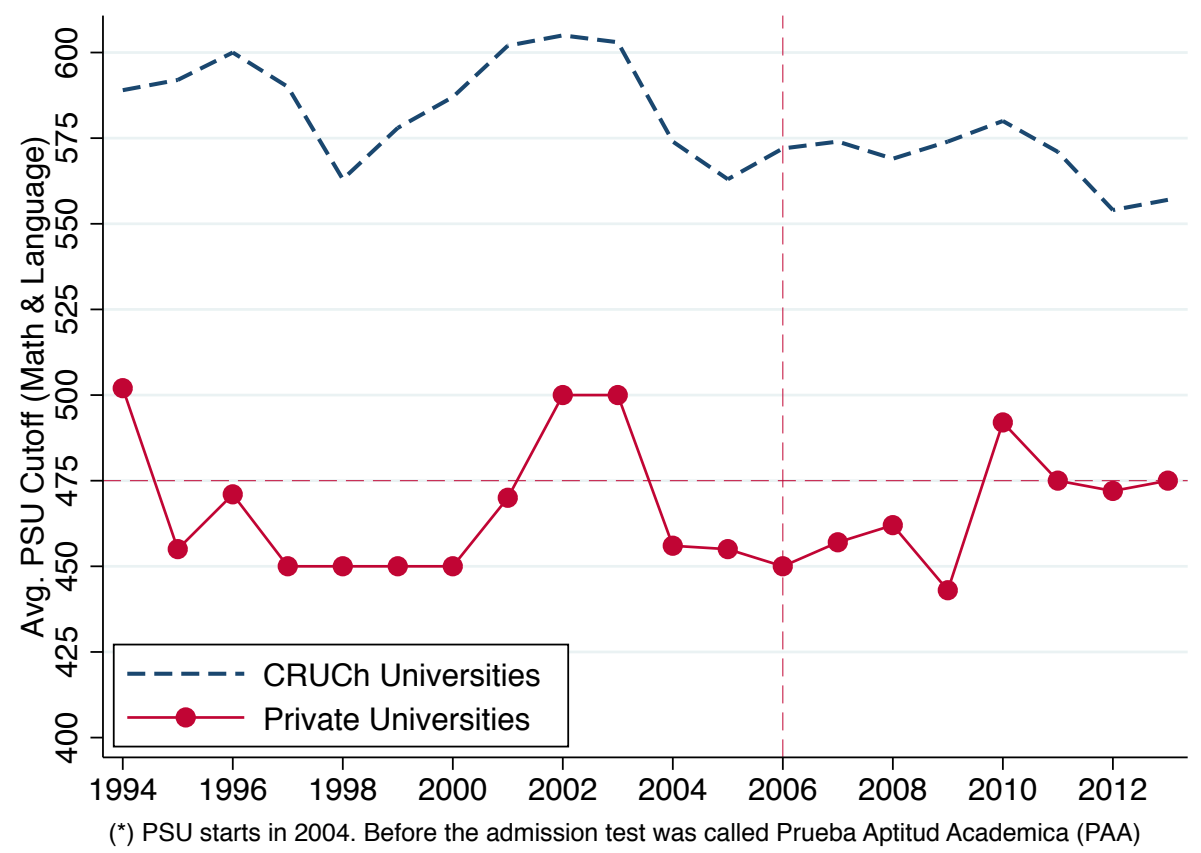

Figure 6: Admission PSU cutoff score by type of institution

high school in the case they apply to a TI or PI ${ }^{22}$ In fact, the cutoff of 475 points was in fact binding for a considerable part of the population since the median score (taking the average score by school) was just 454 points. ${ }^{23}$ Moreover, given the fact that traditional universities were able to impose higher entry cutoff scores (see Figure 6) and that, by the time of the reform, most of the funds in student aid were concentrated in these institutions, the CAE reform came to be perceived, among the segment of the students coming from more disadvantaged backgrounds, as a relaxation in the academic requirements for access to student aid.

\footnotetext{
${ }^{22}$ In this case, the institution is allowed to set, as an option to the PSU minimum, a GPA higher than or equal to 5.3 in high school. The Chilean scale ranges from 1.0 to 7.0 with a 4.0 being the minimum passing grade.

${ }^{23}$ Figure 14 in the Appendix shows the distribution of PSU scores by school in 2005, just before the CAE reform.
} 


\section{Empirical Strategy}

The CAE reform was made universal and implemented at the national level at one point in time, which makes the evaluation problem not trivial. However, we use some features of the reform and the educational system to evaluate its impact. First, the reform was introduced in 2006, and as is shown later, we have students' information before and after its implementation. Secondly, at the time of the introduction of the reform, students were attending schools that historically had very different results preparing their students for the national admission examination (PSU). ${ }^{24}$ Recall that CAE eligibility is conditional on a minimum score (475 points) in the PSU to enter a university. Before the reform, students accepted in one of the "traditional" universities were eligible to credit with conditions more favorable than CAE's (either the FSCU, a government scholarship or their own funding), conditions which remained in place after the introduction of CAE 25 Therefore, students in schools that historically put students in college (and particularly, the best students in those schools) were the least likely to be affected by the reform since they had an alternative source of funding for attending college before and after the reform ${ }^{26}$

As stated above, one of our central hypothesis is that the CAE reform affected the behavior of elementary and high school students through the expectations channel. Figures 7 and 8 not only illustrate this conjecture, but also the fact that students enrolled in the

\footnotetext{
${ }^{24}$ Recall that the contents of the PSU test are based on the scientific-humanistic high school curriculum (see Note 14).

${ }^{25} \mathrm{At}$ the time of the implementation of CAE, the interest rate associated to the CAE was $5.8 \%$ while the one for the FSCU was $2 \%$. After massive student protest in 2011, the interest rate was equalized at $2 \%$ for both programs. This change in CAE's conditions does not affect our analysis since the youngest cohort of students in our first sample are those who started high school in 2005, while in our second sample we analyze students in their first year of high school for the period 2002-2009, so none of them were affected by the change in the credit conditions.

${ }^{26}$ Given the high correlation between the schools' PSU score and their students socioeconomic background, (see Figure 2), it seems that students that were not credit rationed at the time of the reform belonged to high-score schools. Moreover, recall that, if they were indeed restricted in their access to credit, they also had the possibility to access credit through the existing state guaranteed program (FSCU), in the case where they were accepted by one of the "traditional" universities. For the above reasons, we identify students in high-score schools as those least likely to be affected by the reform. As an additional piece of information regarding this point, Figure 15 in the Appendix shows the distribution of PSU scores in 2005 by type of secondary school. Notice the sharp difference in PSU scores between students from unsubsidized private schools and those of students from municipal and voucher schools.
} 

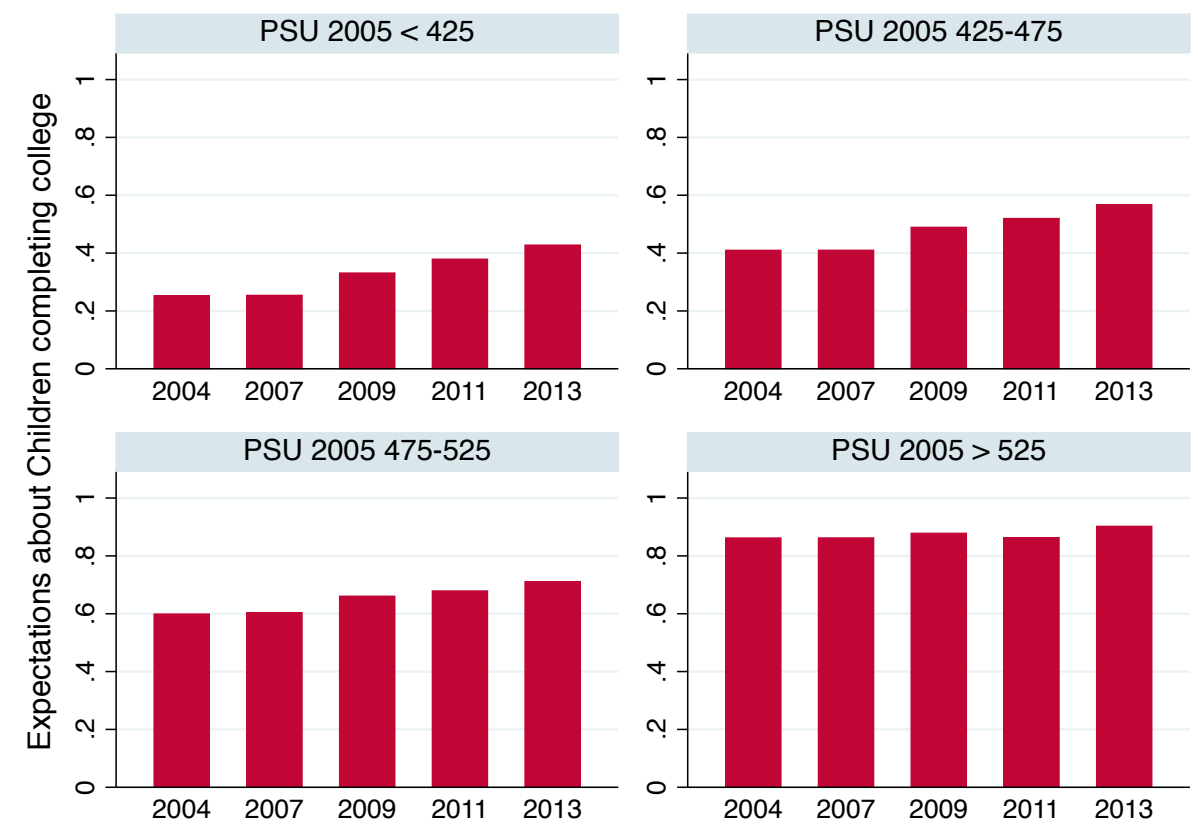

Figure 7: Parents expectations about college completion (8th grade)

best schools before the reform could act as a control group in our analysis. Specifically, Figure 7 shows the fraction of parents of eighth grade students who believe that their children will eventually complete college education for different years and different schools according to their PSU the year before the implementation of the CAE. Notice first that, in the case of schools with an average score over 525 points in the year 2005, it is not only where a higher expectation of completing college is observed but also parents' expectations have been stable over this period (around $85 \%$ of parents expect that their children will complete their college education). Second, different from the previous case, families who had enrolled their children in schools with lower average scores, show a clear increase in parents' expectations about their children completing their college education. Moreover, the timing in the increase of expectations happens after CAE's introduction. Note in the case of families who had enrolled their children in schools with a score lower than 425 points, the share of parents who believed that their children would finish college increased from $25 \%$ in 2004 to $33 \%$ in 2009 and to $36 \%$ in 2011. 


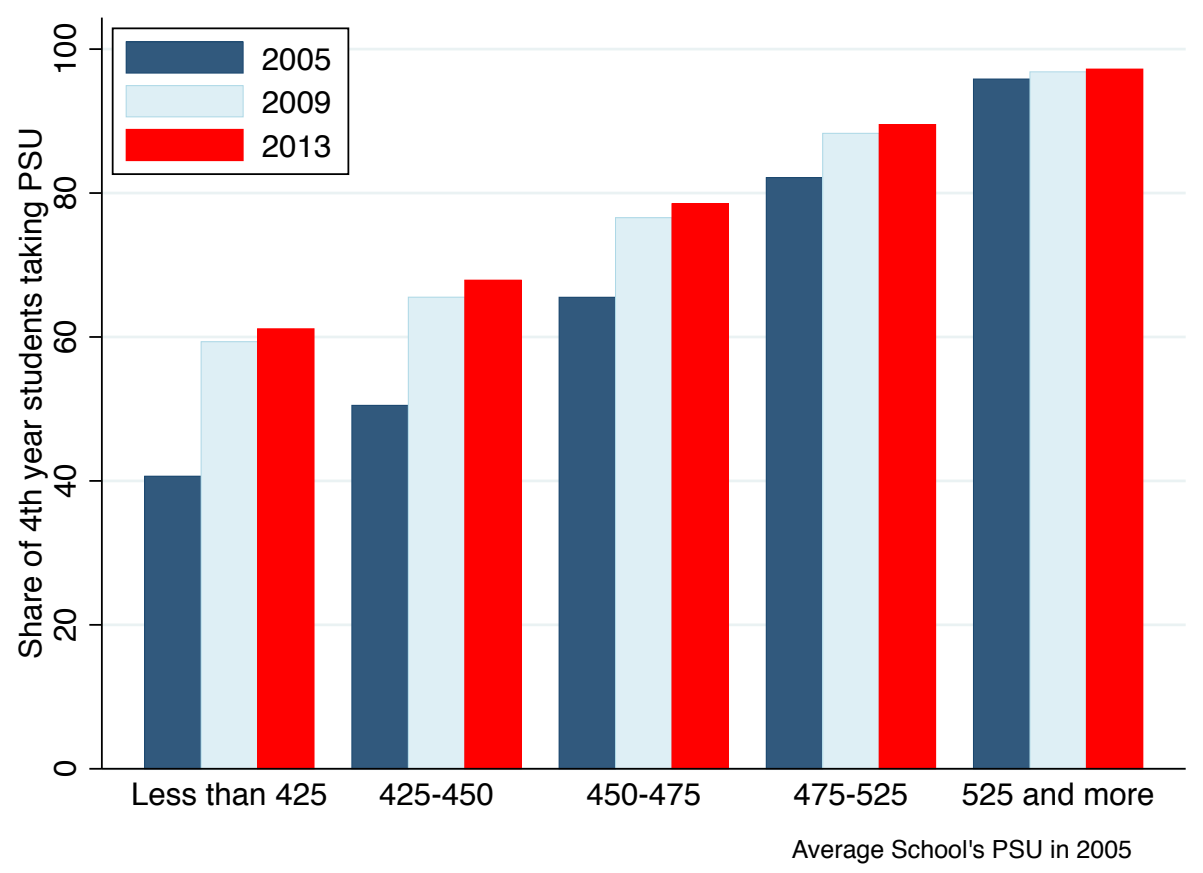

Figure 8: Share of senior year students taking PSU

Consistent with this pattern of parents' expectations, Figure 8 shows that the share of senior students taking the PSU exam during 2005, 2009 and 2013 has been highly stable among students enrolled in schools with an average PSU higher than 525 in 2005 (before the CAE's introduction) with a share close to $100 \%$ over the period. On the other hand, note the sharp increase in participation between 2005 and 2009 among students in schools with an average score lower than 525 points.

We will use two specifications to evaluate the impact of the CAE reform. In our first specification, we exploit school heterogeneity in their average PSU score for the year 2005 (pre-reform). The average PSU score for every student in the population is defined by the average 2005 PSU score of the school where the student was enrolled previous to the implementation of the CAE. The control group corresponds to students attending highscore schools (those with an average PSU higher than 525 points) ${ }^{27}$ Our first specification

\footnotetext{
${ }^{27}$ Dealing with a similar problem with a college aid program in Denmark, Nielsen et al. (2010) rank individuals according to the measure of parental income that determines eligibility for student aid. In this case, the income cutoffs for eligibility are not that strict (and changed over time), so we will work with academic eligibility in order to identify the intensity of treatment.
} 
is the following:

$$
y_{i s t}=\alpha+\beta_{t}+\delta Z_{i s t}+\sum_{j=1}^{J-1} \phi_{j} * P S U_{s, 2005}^{j}+\sum_{j=1}^{J-1} \gamma_{j} * T_{t}^{a f t e r} * P S U_{s, 2005}^{j}+\varepsilon_{i s t}
$$

where $y_{\text {ist }}$ represents an outcome for an individual $i$, at school $s$ (before the reform); $\beta_{t}$ corresponds to the year fixed effect and $Z_{\text {ist }}$ a vector of controls at the individual level (age, sex, and cohort). Furthermore, $T_{t}^{a f t e r}$ is an indicator variable for the reform being already in place (2006 onwards); and $P S U_{s, 2005}^{j}$ is a dummy variable indicating that the average PSU score for school $s$ in 2005 was within the range $j$. The parameter of interest, $\gamma^{j}$, can be interpreted as the ceteris paribus contribution of the implementation of CAE for those students who were enrolled previous to the reform in a school with an average PSU in 2005 within range $j$, compared with children enrolled in schools with a PSU higher than 525 points before the reform.

A second specification further distinguishes between students according to their position in the GPA distribution prior to the reform. Specifically, we allow that the reform affected students with different academic records differently at the time of the CAE's introduction. In fact, following Bedard (2001), a policy that lifted college restrictions for the whole population would have a different impact for more able students than those with a lower level of ability. For this purpose, we rank all students according to their GPA the first year we observed them (previous to the reform), and classify them according to their relative position in the class. 
The second specification can then be represented as follows,

$$
\begin{aligned}
y_{i s t}=\alpha+\beta_{t}+ & \delta Z_{i s t}+\sum_{j=1}^{J-1} \phi_{j} * P S U_{s, 2005}^{j}+\sum_{k=2}^{3} \eta_{k} * \operatorname{Rank}_{i}^{k} \\
& +\sum_{j=1}^{J} \sum_{k=1}^{3} \varphi_{j k} * \operatorname{Rank}_{i}^{k} * P S U_{s, 2005}^{j} \\
& +\sum_{j=1}^{J-1} \sum_{k=1}^{3} \theta_{j k} * \operatorname{Rank}_{i}^{k} * T_{t}^{a f t e r} * P S U_{s, 2005}^{j} \\
+ & \sum_{k=2}^{3} \theta_{J k} * \operatorname{Rank}_{i}^{k} * T_{t}^{a f t e r} * P S U_{s, 2005}^{J}+\varepsilon_{i s t}
\end{aligned}
$$

where $\operatorname{Rank}_{i}^{k}$ is an indicator of the student belonging to the tercile $k=\{1,2,3\}$ of the class GPA distribution prior to the reform. In this specification, the omitted category corresponds to the students in the first tercile of the GPA distribution who were enrolled in a school with more than 525 points before the reform. The parameter of interest in this second specification is $\theta_{j k}$ measuring the incremental effect of CAE for students of rank $k$ and enrolled in a school whose average PSU score in 2005 was within the range $j$, compared to students from the first tercile $(k=1)$ enrolled in a school with an average PSU score over 525 points $(j=J)$.

For the outcomes involving one observation per student (high school dropouts and the the choice of the scientific-humanistic track), our preferred specification will include school fixed effects. For the rest of the cases we will include individual fixed effects. Moreover, in order to account for any confounding factors that might have taken place in the student's municipality of residence during the period under consideration, we will also estimate a specification including municipality-year interactions, together with individual/school fixed effects ${ }^{28}$

\footnotetext{
${ }^{28}$ This specification was estimated following the algorithm by Guimaraes and Portugal $(2010)$.
} 


\section{Data, variables and samples}

Four data sets are used in our analysis. The first one is the parents' supplement from the SIMCE survey ${ }^{29}$ standardized test taken in 4th, 8th and 10th grades (2nd year of high school) from 2000 to $2 0 0 9 \longdiv { 3 0 }$ For the specification in equation (2), we keep students who were observed in two examinations, the first time before and the second time after the reform, and rank them within each school according to their average score in the Language and Math SIMCE tests the first time we observed them 31

The outcome of interest in this data set is the parents' expectation about the college education of their child. Specifically, the outcome "Expectations about college completion" is a dummy variable, taking a value of one when a student's parents believe that he/she will end up completing college education, and zero otherwise.

The second source of information comes from students' records from the Ministry of Education, available from 2002 to $20132^{32}$ Specifically, we construct two datasets to evaluate the impact of the reform on students' performance. For each student and year, we know which grade and school a student attended, her/his GPA, and whether or not a student passed, failed or left the class or school. Therefore we can identify whether or not a student ended up dropping out as well as whether or not he/she switched schools. The first database is constructed to evaluate the impact of the reform on the probability of dropping out, the performance and the school switching for students who were already in high school at the time of the reform. The second database is aimed at capturing the impact of the reform on students transitioning from elementary to secondary school.

To construct the first data set, we use all students who started high school between 2002

\footnotetext{
${ }^{29}$ Sistema de Medición de la Calidad de la Educación. Data is available from http://www.agenciaeducacion.cl.

${ }^{30}$ The 4 th grade SIMCE exam was given in 2002, and then every year from 2005 to 2009 . The 8 th grade exam was administered in the years 2000, 2004, 2007 and 2009. The 10th grade exam was given in 2001, 2003, 2006 and 2008.

${ }^{31}$ The sample consists of students who were in 4 th grade in 2002 and 10th grade in 2008 , 8th grade in 2004 and 10th grade in 2006, and 4th grade in 2005 and 8th grade in 2009.

${ }^{32}$ Data is publicly available from the website of the Ministry of Education: http://centroestudios.mineduc.cl/.
} 
and 2005, that is, before the reform took place. In that way, we obtain a sample of students whose decision to be enrolled in secondary education (and in a particular school) could not have been affected by the reform 33 For this data set we define five outcomes. "Dropout" is a dummy variable taking a value of one when a student appeared in the data for the last time in a given year and this student did not graduate in that particular year, and zero otherwise. The second outcome is the Grade Point Average (GPA) for a student in a given year. The next outcome, "Fail to pass grade," is a dummy variable taking a value of one when a student does not pass the grade and zero otherwise. The last two outcomes in this data set are intended to measure the impact of the reform on the movement of students through schools. Given that the reform relaxed the credit constraints on accessing higher education, we expect a change in the demand for schools increasing the chances of students to get into college. Moreover, by affecting school achievements such as repetition rate, the students might change their likelihood of switching schools given the restriction imposed by some schools on the possibility of repeating a grade in the same school. Specifically the two variables measuring the impact on school switching are "Change school," which is a dummy variable taking a value of one in the case where the student's current school is different from the school in which the student was observed the first year, and " $P S U$ 2005" being the average PSU score in 2005 of the student's current school, which since it was measured in the base year can only change in the case in which the student switched schools.

The second sample from the students' records from the Ministry of Education is used to analyze students' transition from elementary to secondary school over the period 2002 to 2009. Specifically, we keep students who were in sixth, seventh or eighth grade of elementary school before the reform took place. We rank these students the first time we

\footnotetext{
${ }^{33}$ One reason for eliminating from our population all students who started freshmen year before 2002 is to minimize the risk of potential contamination due to the implementation of compulsory secondary education, established by Law 19,876 of May 2003. However, looking at all the cohorts in our analysis, we do not observe a distinguishable pattern in dropout rates over time (see Figure 16 in the Appendix). Moreover, our results in the following sections are robust to the inclusion of these older cohorts.
} 


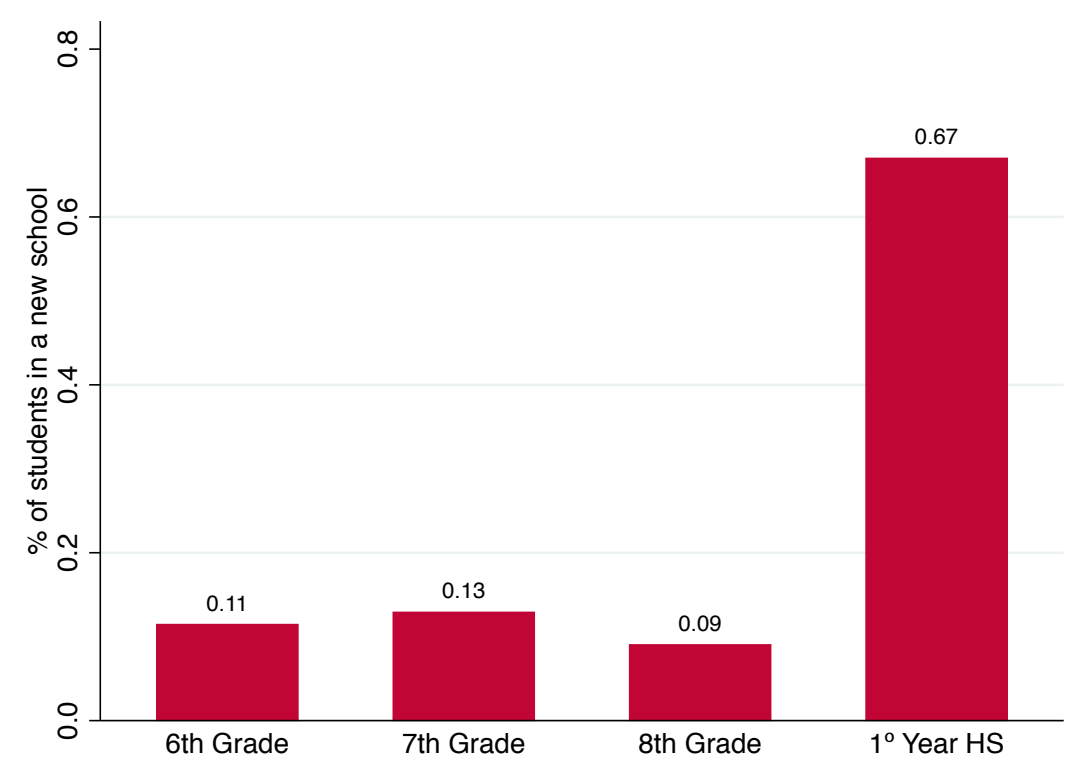

Figure 9: Students switching schools in the transition from elementary to secondary

observed them in the data (in sixth grade, except for the cohorts who started high school in 2003 and 2004) and study their outcomes until they are enrolled in ninth grade (first year of high school). Given that this transition involves massive school switching (see Figure 9), we are particularly interested in studying the impact of the reform on their choice of secondary school and academic track.

For this sample of students, we define two outcomes. First, "Scientific-Humanistic", which is a dummy variable taking a value of one in the case in which a student has chosen the Scientific-Humanistic track the first year of high school, and zero otherwise ("TechnicalProfessional" track). The second and third outcomes are similar to those for the sample of students already in high school: "PSU 2005", is the average PSU score in 2005 for the school where the student has started his/her secondary education and "Fail to pass grade," is a dummy variable taking a value of one when a student does not pass the grade and zero otherwise.

For each database, the information for every student is merged with the average school PSU for the year 2005 obtained from the Universidad de Chile. For the samples of

\footnotetext{
${ }^{34}$ Average PSU scores by school were obtained from the Departamento de Evaluación, Medición y
} 


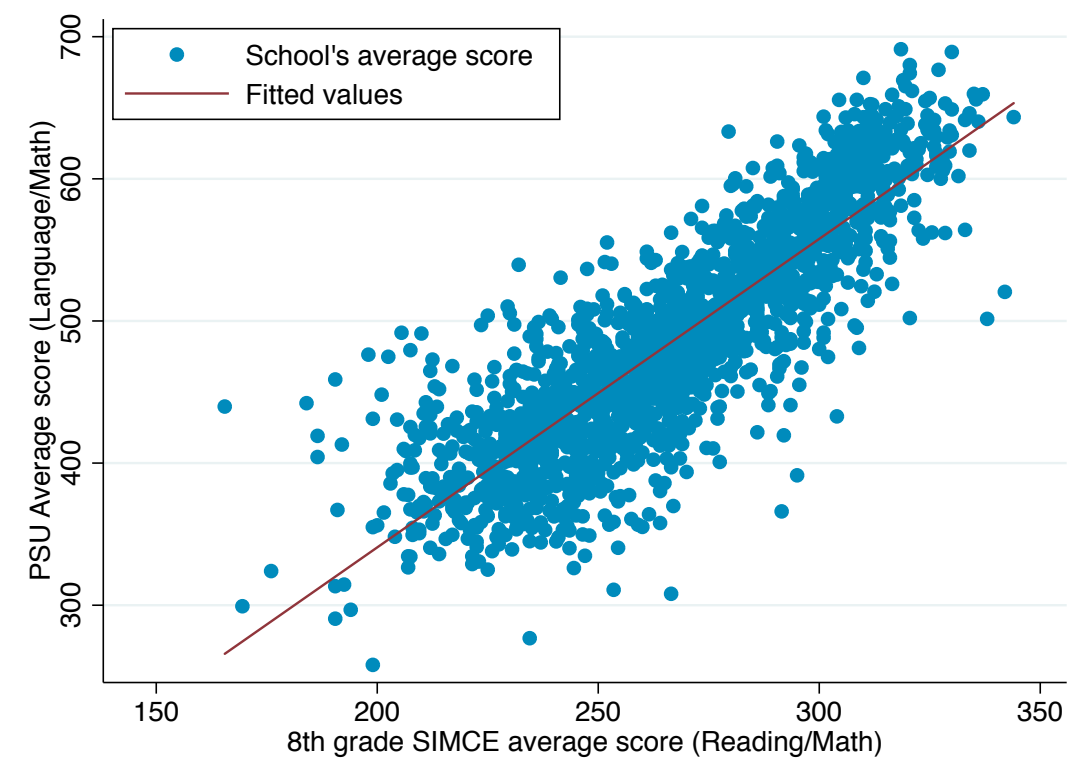

Figure 10: Correlation between 8th Grade SIMCE (2004) and PSU 2005

elementary school students (the SIMCE parents' survey and the sample of students transitioning to high school), there are some schools with missing PSU since these institutions do not have secondary education. That is, they are elementary-only schools. To assign a PSU score to each elementary-only school, we predict the PSU using the 8th grade SIMCE average scores in language and math in 2004, using the high correlation between the PSU and SIMCE scores (see Figure 10). 35

The third data source is Chile's national socio-economic characterization survey (CASEN) ${ }^{36}$ We use this data to investigate how the reform affected teen fertility and to check the results on dropout rates. In order to do so, we construct a sample of women between 15 and 19 years of age for the period 1990-2011. The survey contains individual and family information about education, health, employment and income as well as the household's demographic composition. This information from CASEN is also used to construct municipal socio-economic variables such as the average income per capita, average years of education, and poverty rates. Using this data, we investigate whether or not the increase Registro (DEMRE) from Universidad de Chile, and is available from http://www.demre.cl ${ }^{35}$ The regression also includes municipality fixed effects. The $R^{2}$ of the regression is 0.88 .

${ }^{36}$ Data from CASEN survey is publicly available from http://observatorio.ministeriodesarrollosocial.gob.cl 
in college aid coming from CAE had an impact on teenage motherhood for girls between 15 and 19 years of age.

Finally, in order to check the robustness of the results on teen fertility, we use data from birth certificates for the period 1994-2011 Us7 Using population data, we construct fertility rates by different age groups at the municipality level. For this last data source, we use aggregate variables at the municipality level coming from CASEN as additional controls. Summary statistics for the different samples are reported in Table 1.

\section{Results}

\subsection{Parents' expectations about college completion}

Tables 2 and 3 present the estimates of the impact of the CAE reform on parents' expectations about the student's (currently in 4th, 8th or 10th grade) college completion, using the specifications in equation (1) and (2), respectively. Each column in the tables presents the estimates using a different set of controls, indicated at the bottom of the table. The first thing to notice looking at the means reported in Table 2 is that there is a positive correlation between parents' expectation measured by the fraction of families reporting that they expect that the child will complete college and the school's PSU. While approximately $30 \%$ of the parents believe that a student will complete college in schools with a PSU lower than 425, this fraction is approximately $70 \%$ among parents in schools with a PSU between 475 and 525. Secondly, notice in Table 3 that, for every range of PSU scores, a higher fraction of parents whose child is in the upper part of the grade distribution believe that the student will complete college with respect to those who are at the bottom. It is also worth noting that the difference in expectations between good and bad students decreases with school average performance ${ }^{38}$ That is, while we observe differences in the

\footnotetext{
${ }^{37}$ Birth records are publicly available from http://www.deis.cl

${ }^{38}$ While there are 20 percentage points difference in the fraction of parents who believe that their child will complete college among schools with a PSU lower than 425, this difference is reduced to fewer than 10
} 
expectations of parents in schools with lower PSU, among the best schools, all parents independent of the relative performance of the child foresee that their children will complete college.

The results of our first specification (Table 2) show an increase in expectations of parents in schools at the bottom of the distribution (with a PSU lower than 425), which are robust to all specifications used. Specifically, the last column of Table 2 shows an increase of 4 percentage points in the likelihood that parents report that a student will complete college (around 14 percent in terms of the sample mean). While we observe an impact among schools with a PSU lower than 475, this impact is not robust to the inclusion of municipality-year interactions. However, when we estimate equation (2) using as a control group the best students from high-performance schools, we observe impacts across all type of schools. As shown by Table 3, parents with children in schools with a PSU lower than 475, independent of their children's ranking within the school, are more likely to report that their children will complete college. Notice also that the impact monotonically increases with the student's ranking within their school. On the other hand, among parents with children enrolled in schools with a PSU higher than 475, we observe that parents whose child does not belong to the top tercile either do not change or reduce their expectations $(1 \%$ to $3.5 \%) .39$

Our previous results suggest that the CAE reform increased college expectations among the families of students in the upper part of SIMCE score distribution, and specifically in schools where students were most likely to be credit restricted. As a first approximation to the results we will present in the following sections, these results in expectations anticipate that, even though the CAE reform was intended to reduce credit constraints for all students, its impact on behavior was very sensitive to the student's previous academic

percentage points for schools with more than 525 points in the PSU, where more than $80 \%$ of the parents expect that their child will complete college.

${ }^{39}$ Recall that this question exclusively is in regard to college education, while the CAE reform increased the availability of credit for all types of postsecondary education (i.e. PI and TI). Therefore, the reduction in college expectations of parents of worse students might imply some degree of switching between college and professional education. 
performance.

\subsection{Students already in high school at the time of the reform}

\subsubsection{School dropout}

Tables 4 and 5 presents the results of the impact of the CAE reform on school dropout using the specification presented in equations (1) and (2), respectively. The structure of each table is the same as the one in the previous section.

The results in Table 4 for the different specifications reveal a reduction of approximately 2.2 to 3.6 percentage points (8.4 to $13.6 \%$ in terms of the sample means) in dropout rates among students who started high school in an institution with s PSU score below 450 points (the bottom half of the distribution as shown in Figure 14). Nevertheless, the impact among schools with higher PSU scores is not robust to the controls used and statistically insignificant for the specifications considering the full set of controls (column (4)). Therefore, consistent with the results presented in the previous section, our estimates show that the introduction of the CAE induced a reduction in dropout rates among those schools where the students face a higher risk of dropping out of the system.

The results reported in Table 5 reveal an important heterogeneity across students. The first element that is worth noting is the higher dropout rates (sample means in italic) among students from low-score schools, and specifically among students at the bottom terciles within each type of school. The results allow us to distinguish three different groups. First, for students in low-score schools with (PSU below 425, around 30\% of the population), we observe a sharp decrease in the probability of dropping out for students in the first (29\% for the specification with the full set of controls) and second (19\%) tercile of the GPA distribution, while for students at the bottom tercile we observe either a smaller impact or non significant effect. When we look at students enrolled in a middle range schools (average PSU between 425 and 525) the pattern is reversed. That is, the CAE reform reduces dropout rates among students at the bottom two thirds of the GPA 
distribution. Notice that for schools with a PSU between 425 and 475 points, the reduction in the likelihood of dropping out is larger among students in the second tercile of the GPA distribution (around 16\%) than the one observed among students in the third tercile (6\%). However, for schools with a PSU in the range 475-525 the relative impact is relatively similar for both groups of students (23 vs. 20\%). Finally, for higher-score schools (average PSU above 525 points in 2005), we only find a negative impact for students at the bottom third of the distribution (around 17\%), compared with the control group (students from the top tercile in schools with PSU above 525 points).

The above results suggest that the reform affected the ex ante more likely users of CAE: students in the neighborhood of future eligibility. As shown in section 5.1, students (and their families) build their expectations about future chances of accessing college using all the available information: school performance (school's average PSU) and their own performance (ranking in their class). Therefore, we find that lifting the restriction in the access to college credit affects the likelihood of completing high school for students that expect to be "closer" to the new minimum requirements.

The observed impact on the likelihood of dropping out can also be interpreted within the signaling framework as the one presented in Bedard (2001), but within a context of strong school heterogeneity as is the case of the Chilean educational system. Recall that, in Bedard's model, when students are constrained in accessing higher education, both high and low ability students are "pooled" in high school graduation. Therefore an increase in access makes some high ability students leave the high school pool, reducing the value of the signal for less able students who originally were completing high school to pool with high-ability classmates. As a result, greater access to university may increase the number of high school dropouts.

The results above show a very different pattern depending on the type of school. Consider first low-score schools, with a relatively high dropout rate (e.g. $33 \%$ for schools with a PSU lower than 425). In this case, some high-ability students were originally pooled 
with low-ability classmates in a high school dropout equlibrium. With the increase in the access due to the reform, some of the high ability students who were originally dropouts, finish high school in order to pursue higher education. On the other hand, their low-ranked peers who also were originally dropping out (60\% average dropout rate), do not change their behavior, since the signal of high school graduation remains unaltered. This is consistent with Bedard's results, with the difference that the original pooling equilibrium is at high school dropout instead of graduation. Matters are different in high-score schools, with a low average dropout rate (e.g. $8 \%$ for schools with a PSU higher than 525). Here the vast majority of students were originally finishing high school, with some low-ability students separating by dropping out. With increased university access, the dropout rate falls for students at the bottom of the distribution, who are more likely to pool with their high-performance classmates in pursuing a college degree ${ }^{40}$ Despite the heterogeneity in the results, both of them indicate a low value of the high school graduation as a signal other than merely being a prerequisite for higher education.

The previous results somehow point to the amount of human capital at the time of the reform being important when defining the impact of the interventions. These results reflect how students' behavior is affected by the reform, given their previous academic performance and school quality. As we show in the following sections, both academic performance and school choice can also be affected by the reform. Therefore, students who were exposed to the reform longer had more time to alter these two dimensions. As a specification check of the above results, it may be useful to see how the availability of the CAE affected students according to their exposure to the reform. Figure 17 shows the results of the estimation of an alternative specification where the indicator variables for the different score ranges are interacted with exposure to the reform, using all the information

\footnotetext{
${ }^{40}$ Recall that the reform not only increased the sources of funding but also reduced the academic requirements. Students receiving funding from the CAE were allowed to apply to non-traditional colleges which had a lower cutoff than traditional universities. That is, for some students the CAE meant as well a reduction in the cost of "pooling" at the college level with high-ability classmates planning to attend college.
} 
available (cohorts already in high school in 2002 and those entering high school between 2003 and 2009). Therefore, the cohorts who were in their freshmen year in 2003 had one year of exposure to the reform (in their fourth year), with two years for those who started in 2004 and so on to eight years of exposure. Notice that students who belonged to schools scores lower than 425 are affected if they had two years of exposure or more, while there are no clear impacts for the other categories.

\subsubsection{Performance}

One can expect an impact on students' performance for several reasons. First, as more students at risk of dropping out stay in the system, this mechanically affects the average performance of a given group negatively. Second, a relaxation in the credit constraint (or reduction in the academic requirements) for higher educations could affect the effort of students trying to ensure eligibility for the credit and access to an eligible HEI. Table 6 presents estimates of the impact of the CAE reform on GPA (columns (1) and (2)) and the probability of failing a grade (columns (3) and (4)), using the specification in equation (1). We find a slight negative impact on GPA and a sizable increase (between 10 and 18\%) in the probability of repeating a year, mainly among students from schools with a PSU lower than 475 points.

The results on performance are not that surprising considering the fall in dropout rates reported in the previous section. However, in the case in which a compositional effect was the main explanation behind the drop in the average performance in low-score schools, we might expect a larger reduction in GPA and a larger increase in retention rates among the groups of students with the highest decrease in dropout rates. Table 7 shows the estimation of the impact of the CAE using the specification in equation (2) on GPA (columns (1) and (2)) and Fail (columns (3) and (4)). Notice that, contradicting the composition explanation, exposure to the CAE implies an improvement in performance among students in the last tercile and a decrease in GPA, together with an increase in the 
probability of grade repetition among students at the top tercile of the GPA distribution in freshmen year, regardless of the type of the school.

While it is possible that better grades were caused by an increase in effort, there is not a clear explanation as to why students at the top the GPA distribution before the reform would exhert lower effort after the introduction of the CAE. It is also possible that this puzzling impact on performance was produced by choosing a school where for a similar level of effort it is easier to obtain better grades. This strategy is relevant in the Chilean context since admission to college depends on a weighted average of the PSU and high school GPA. If this kind of strategic behavior was behind the results in performance, we should not only observe students switching schools but also observe some heterogeneity in the type of institution to which they move. This hypothesis is explored in the next subsection. 41

\subsubsection{School switching}

Table 8 presents the estimates of the impact of CAE on the two outcomes characterizing the change of school. Columns (1) and (2) show the results for the outcome indicating a change of school (with respect to the one attended freshmen year, before the reform) and columns (3) and (4) a variable indicating the average school PSU for the year 2005. For both outcomes we focus on the specification presented in equation (2) and we show the estimates for a specification with only individual and year fixed effects, and for the one with the full set of controls.

For the impact on the probability of switching schools, we observe all the coefficients being positive and significant. That is, the introduction of CAE induced some students to switch schools. However, notice that the point estimates are always higher among students at the bottom of the GPA distribution in a given school type (PSU range). The results

\footnotetext{
${ }^{41}$ Notice that the estimates in Table 7 show an increase in GPA together with a greater probability of failing a grade for the second tercile. When this analysis is performed by quartiles (results available from the authors upon request) we found an increase in the GPA for the third quartile for all categories (with no effect for the second quartile).
} 
also reveal that the pattern is decreasing in school PSU for good students and increasing for low-ranked students. These last results suggest that the expansion of the student aid increases the likelihood that a student changes school but the increase in this probability is greater among students at the bottom of the distribution, particularly in better schools.

The results for the second of these two outcomes show that students in low-score schools (below 425 points) moved on average to higher performance schools, with an increase in approximately 6 points $(0.1 \mathrm{SD})$ in PSU, regardless of the students' ranking before the reform. However, for schools with a higher average PSU score, the effect remains positive only for students at the top tercile of the GPA distribution. Students at the bottom tercile, on the other hand, tend to move to schools with lower PSU scores.

Overall, the reported findings on schools switching are not only consistent with the results found for the average GPA and retention rates but they also shed some light on the channels by which students increase their chances to access higher education. Some students who try to maximize their chances to get into an HEI choose schools that allow them to improve their credentials. However, the results suggest that the optimal strategy may have been different for students according to their position in their freshman class ranking. On the one hand, for better treated students, the optimal strategy was moving to better schools (higher school PSU), which may have negatively affected their performance. On the other hand, low-ranked students, and particularly those from high-score schools, moved to schools where improving their grades is probably easier. Recall that, even though high school GPA is not considered to ensure CAE eligibility in all cases, it is indeed considered for college admission. ${ }^{42}$ This strategic behavior of "bad" students moving to less demanding schools as a consequence of the reform, may have operated in addition to the compulsory switching due to schools' "cream skimming". The confluence of both factors may be the reason for the higher probability of switching in students at the bottom of the distribution.43

\footnotetext{
${ }^{42}$ Moreover, GPA by itself may enable access to the CAE in the case of PI or TI. See footnote 22 .

${ }^{43}$ After the introduction of the students' GPA ranking as part of the weighted average in the admission
} 


\subsection{Students in the transition from elementary school}

We have shown that CAE's impact on school achievements is heterogeneous across students and is primarily driven by the strategic choice of schools. In addition, we showed when analyzing the impact on dropping out, the impact was stronger among individuals that had a higher degree of freedom at the time of the introduction of the reform (more time exposed to the CAE). In this section we show the results for a population of students who, at the time of the reform, were still in elementary school, so with a higher degree of freedom than students at high school. We rank these students by their performance in sixth grade (eighth and seventh grade for those who started high school in 2003 and 2004, respectively). Specifically, the variables of interest aim to capture the type of school chosen by students when moving to high school.

\subsubsection{Academic track}

The choice of academic track is crucial when we wish to evaluate the impact of the greater availability of college credit on high school students' behavior. The reason for the importance of this outcome is that the PSU exam is mostly based on the Scientific-Humanistic curricula, rather than the one found in Technical-Professional schools. Therefore, there is a substantial difference in the performance of the students from each track in the PSU, as can be observed in Figure 11 .

process in 2013, a generalized switching of senior year students from emblematic public high schools (such as the Instituto Nacional) to other less demanding schools, caught the attention of the press last year. See LA TERCERA, 08/26/2014. 


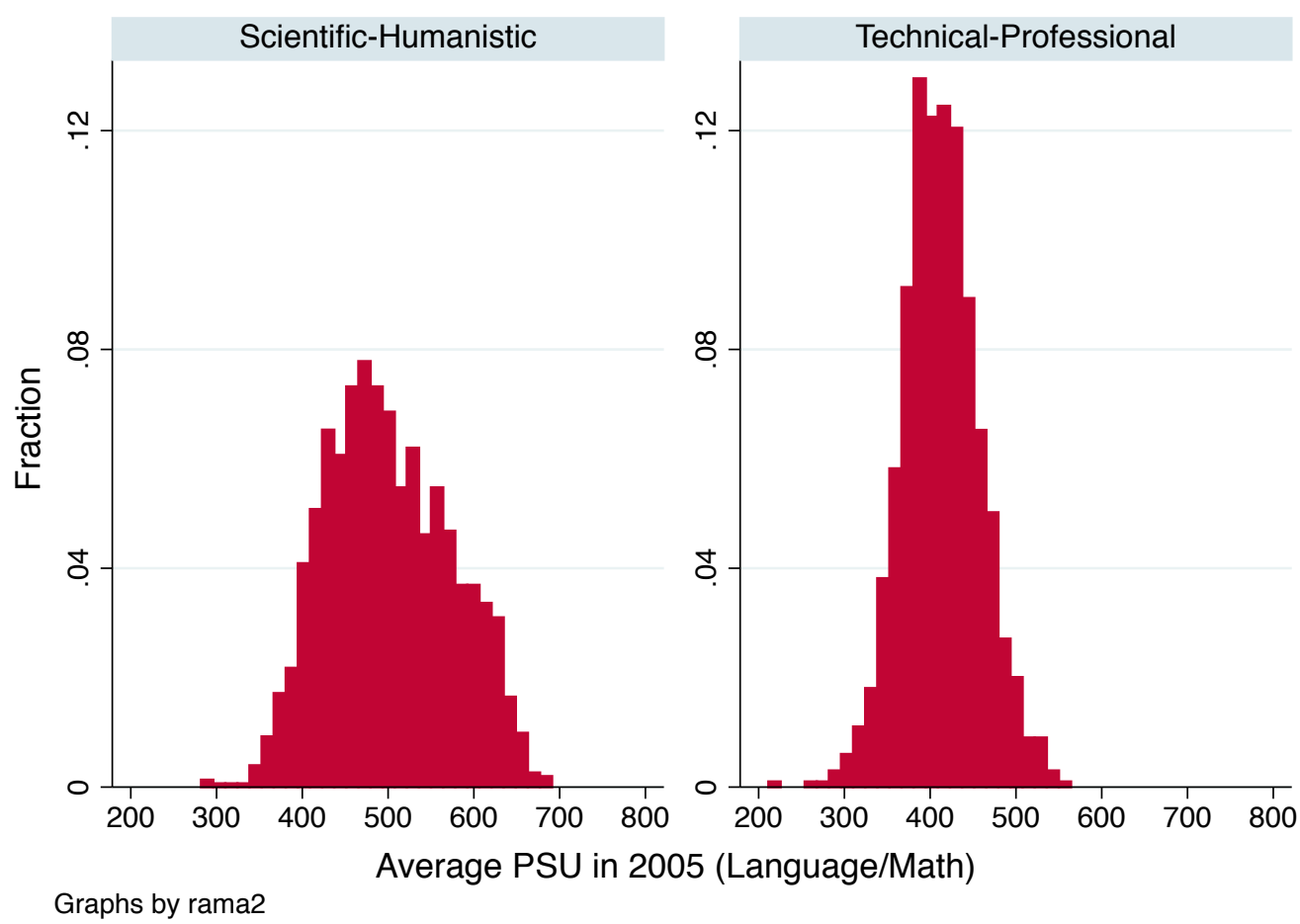

Figure 11: Distribution of school's average PSU in 2005 by academic track

Table 9 shows estimates of equation (2) for enrollment in the Scientific-Humanistic track in the first year of high school. Columns (1) to (3) show results for the basic specification, with school fixed effects and the one with both school fixed effects and municipality-year interactions, respectively. Columns (4) and (5) correspond to a sample of students whose original school had only elementary education, and therefore who were forced to start high school in a different school.

Given that it is common knowledge that pursuing the Scientific-Humanistic track improves the probabilities of obtaining a good score in the PSU, it is not surprising that the reform caused more students to choose this track, particularly those coming from more disadvantaged elementary schools. However, notice in columns (1) to (3) of Table 9 that this impact is circumscribed only to students in the first and second terciles, in a range from $1.9 \%$ (schools with PSU between 475 and 525 in 2005) to 6.2\% (schools with PSU below 425). For students at the bottom of the class GPA distribution, however, we find either no 
impact or a negative effect in the case of students coming from the highest-score schools (around 1\% decrease). The results for students coming from elementary-only schools are qualitatively similar, but show a negative impact among students in the second and third terciles and a positive or no impact at the top tercile.

The previous results are consistent with those in Dinkelman and Martinez (2013), who found in an experimental intervention in Chile (developed in 2009, when the CAE was already in place), that students exposed to information about financial aid for higher education are more likely to enroll in a college preparatory high school (Scientific-Humanistic). Considering the fact that we are not evaluating the access to information about the policy but the direct impact of the implementation of the policy itself, their results (with the policy already in effect) in light of ours (over the population of potential beneficiaries regardless if they were informed or not), give us an idea about how sensitive Chilean elementary or high school students are to government policies regarding higher education.

Moreover, these results can be viewed as another dimension by which a separating equilibrium in Bedard (2001) framework is reached: given that the reform implies a lifting of credit restrictions not only for college but also for PI and TI, most able students choose the academic track that enhances their chances of entering the university, while the students at the bottom of the distribution are more likely to follow a secondary education that either prepares them better for tertiary professional education or directly for work after graduation.

\subsubsection{School's PSU score and grade repetition}

Table 10 shows estimates of equation (2) for their current school's average 2005 PSU for students from sixth to ninth grade, ranked in sixth grade. The results are generally consistent, but quantitatively stronger than those shown in columns (1) and (2) of Table 8 for students already in high school at the time of the reform. While students in the first tercile improve from 10 to 36 points $(0.5 \mathrm{SD})$ in school's average PSU, students at the 
bottom of the GPA distribution decrease (excepting those in schools with a score below 425) between 2 and 17 points in the school's average PSU.

Table 11 shows estimates of equation (2) for the probability of failing a grade. In this case, the results have the opposite sign than the one observed for the sample of high school students, shown in Table 7. Notice that in this case, where all individuals start the first year of high school after the reform, the best students are less likely to repeat a grade while students at the bottom tercile are more likely to fail. Different from the sample of high school students, in this case there is no "contamination" via the reduction in high school dropouts. Even though in both cases the reform caused the best students to move to higher-score schools (see Table 8, columns (1) and (2), and Table 10), the results suggest that good students who faced the new environment at younger ages were not harmed by switching to better schools, as appears to be the case for students who were already in high school at the time of the reform.

\subsection{Teen motherhood}

One of the main findings of this paper is that the broad availability of credit for higher education in Chile produced a sizable reduction in the fraction of students dropping out of high school. Given the high correlation between dropping out and risky behavior among adolescents, we believe that it is important to explore other potential impacts on young people associated to the CAE reform.

In this section we investigate, using household survey data for the period 1990-2011 (CASEN survey) ${ }^{44}$, whether or not the reform had an impact on teen pregnancy. For that purpose we estimate a modified version of equation (1) for a sample of women aged 15-19.

\footnotetext{
${ }^{44}$ The Encuesta de Caracterización Socioeconómica Nacional (CASEN), has been conducted in Chile every three years since 1990 .
} 
Specifically, we estimate the following equation 45

$$
y_{i c t}=\alpha+\beta_{t}+\eta_{c}+\theta_{r t}+\delta Z_{i c t}+\varphi X_{c t}+\sum_{j=1}^{J-1} \gamma_{j} * T_{t}^{a f t e r} * P S U_{c, 2005}^{j}+\varepsilon_{i c t}
$$

where $y_{i c t}$ is a dummy variable indicating if a girl $i$, living in municipality $c$ at time $t$, is either pregnant or lives with her own child (two years-old or younger), $\eta_{c}$ are municipality fixed effects, $\theta_{r t}$ region-year interactions and $X_{c t}$ time-varying variables at the municipality level that might affect teenage pregnancy. Among these time-varying variables, we include the poverty rate, the $(\log )$ income per capita, the availability of the morning-after pill (starting in 2009) ${ }^{46}$ and the share of total secondary enrollment at the municipal-level that is under full-day schooling (see Berthelon and Kruger $(2011))^{47}$. Note that in this case, instead of using the PSU score in 2005 as a measure of exposure to the reform, we use the mean of the PSU in the municipality of residence. Here the omitted category includes municipalities with average PSU higher than 525 points in 2005.

Columns (1) to (3) of Table 12 show the estimates for different specifications of equation (3) for the probability of dropping out of school, which are largely consistent with our previous estimates. Columns (4) to (6) present the estimates for teen motherhood. For all specifications, we find a decrease of approximately $35 \%$ in teen motherhood for women living in municipalities whose average PSU score in 2005 was below 450 points.

As a robustness check, we use fertility rates constructed from birth certificates for the period 1994-2011. Estimates for different age groups are shown in Table 13 . Note that the coefficients for the group of women in the age range 15-19 are similar to those obtained from CASEN. We also find an approximately 10\% decrease in fertility rates for women of ages 20-24, but no impact on older women, which is consistent with our hypothesis.

\footnotetext{
${ }^{45}$ We are bounded by using a modified version of the previous specifications since CASEN does not have information about the academic performance or the specific school the individual attended.

46 Bentancor and Clarke (2014), using censal data on all births and fetal deaths in Chile over the period 2005-2011, find that the availability of the pill reduced pregnancy and early gestation fetal death.

${ }^{47}$ Using CASEN data from 1990 to 2006, Berthelon and Kruger (2011) find that access to full-day schools reduces the probability of becoming an adolescent mother among poor families and in urban areas.
} 


\section{Conclusions}

In this paper we analyze the impact of an expansion in a government-guaranteed credit for higher education in Chile on outcomes for students in secondary or elementary school, that is, for children who observed an increase in the return of college education before taking their decision on attending college or not. Specifically, we are interested in evaluating the impact of an increase in the return of education induced by this expansion of the credit which took place in 2006 on educational outcomes such as high school GPA, the likelihood of passing a grade and the likelihood of dropping out. Moreover, we investigate if the reform had any impact on teen motherhood.

To evaluate the policy, using school records of Chilean elementary and high school students that allow us to rank them both by their own performance and by their school's before the reform, we can identify as our control group the best students in highest-ranked schools who most likely had an alternative source of funding before and after the intervention.

In the previous sections, we presented evidence that students most likely to attend college in a future are affected in different ways. First, we find that parents of students who were more likely to be credit restricted before the reform, after the implementation of CAE are more likely to state that the student in the future will complete their college education. Second, we find that lifting future credit restrictions reduces the probability of dropping out of high school. Specifically, we find that the decrease in the dropout rates is concentrated among the best students in lower-ranked schools and low-achieving students in higher-ranked schools. Third, we find that the reform led to an increase in educational sorting, with the best students switching to a school of better quality and under-performing students to lower-ranked schools. Both previous results help to explain why we observe a decrease (increase) in GPA and an increase (decrease) in grade repetition among better (worse) students. Then, we analyze a sample of students that, at the time of the reform, were in transition from elementary to secondary school, finding that good students are more 
likely to enroll in the college-oriented track (Scientific-Humanistic). While the results on school switching are similar to those for the sample of students already in high school, the results for school performance have, however, the opposite sign. Finally, using household data and age specific birth rates aggregated at the municipal level, we find, consistent with previous findings, a reduction in teen pregnancy. 


\section{References}

Base de Datos de la Agencia de Calidad de la Educación 2000-2013. Santiago, Chile.

Attanasio, O. and Kaufmann, K. (2009). Educational choices, subjective expectations, and credit constraints. NBER Working Paper No. 15087.

Attanasio, O. P. (2009). Expectations and perceptions in developing countries: Their measurement and their use. The American Economic Review, 99(2):pp. 87-92.

Bedard, K. (2001). Human capital versus signaling models: University access and high school dropouts. Journal of Political Economy, 109(4):pp. 749-775.

Bentancor, A. and Clarke, D. (2014). Assessing plan b: The effect of the morning after pill on children and women.

Berthelon, M. E. and Kruger, D. I. (2011). Risky behavior among youth: Incapacitation effects of school on adolescent motherhood and crime in chile. Journal of Public Economics, 95:41-53.

Contreras, D., Larranaga, O., Flores, L., Lobato, F., and Macias, V. (2005). Politicas educacionales en chile: Vouchers, concentracion, incentivos y rendimiento. In Uso e impacto de la informacion educativa en America Latina, ed. Santiago Cueto. Santiago: PREAL., pages $61-110$.

Contreras, D. and Rau, T. (2012). Tournament incentives for teachers: Evidence from a scaled-up intervention in chile. Economic Development and Cultural Change, 61(1):219246.

Dinkelman, T. and Martinez, C. (2013). Investing in schooling in chile: The role of information about financial aid for higher education. Review of Economics and Statistics, $96(2)$. 
Gallego, F. and Hernando, A. (2008). On the determinants and implications of school choice: Semi-structural simulations for chile. Economia.

Gauri, V. and Vawda, A. (2003). Vouchers for basic education in developing countries. a principal-agent perspective. World Bank Policy Research Working Paper 3005.

Guimaraes, P. and Portugal, P. (2010). A simple feasible alternative procedure to estimate models with high-dimensional fixed effects. Stata Journal, 10(4):628-649.

Hsieh, C.-T. and Urquiola, M. (2006). The effects of generalized school choice on achievement and stratification: Evidence from chile's school voucher program. Journal of Public Economics, 90:1477-1503.

Jacob, B. A. and Wilder, T. (2011). In Whither Opportunity? Rising Inequality and the Uncertain Life Chances of Low - Income Children, chapter Educational Expectations and Attainment. Russell Sage Press.

Lochner, L. J. and Monge-Naranjo, A. (2011). The nature of credit constraints and human capital. American Economic Review, 101(6):2487-2529.

Mizala, A., Romaguera, P., and Urquiola, M. (2007). Socioeconomic status or noise? tradeoffs in the generation of school quality information. Journal of Development Economics, 84:61-75.

Mizala, A. and Urquiola, M. (2013). School markets: The impact of information approximating schools' effectiveness. Journal of Development Economics, 103:313-335.

Moretti, E. (2004). Estimating the social return to higher education: evidence from longitudinal and repeated cross-sectional data. Journal of Econometrics, 121:175-212. Higher education (Annals issue).

Nielsen, H. S., Sorensen, T., and Taber, C. (2010). Estimating the effect of student aid 
on college enrollment: Evidence from a government grant policy reform. American Economic Journal: Economic Policy, 2(2):185-215.

OECD (2010). Climbing on giants' shoulders: Better schools for all chilean children. In OECD Economic Surveys: Chile, chapter 4. OECD.

Rau, T., Rojas, E., and Urzúa, S. (2013). Loans for higher education: Does the dream come true? NBER Working Paper No. 19138.

Solis, A. (2012). Credit access and college enrollment. Mimeo, Uppsala University.

Stinebrickner, R. and Stinebrickner, T. (2008). The effect of credit constraints on the college drop-out decision: A direct approach using a new panel study. The American Economic Review, 98(5):pp. 2163-2184. 


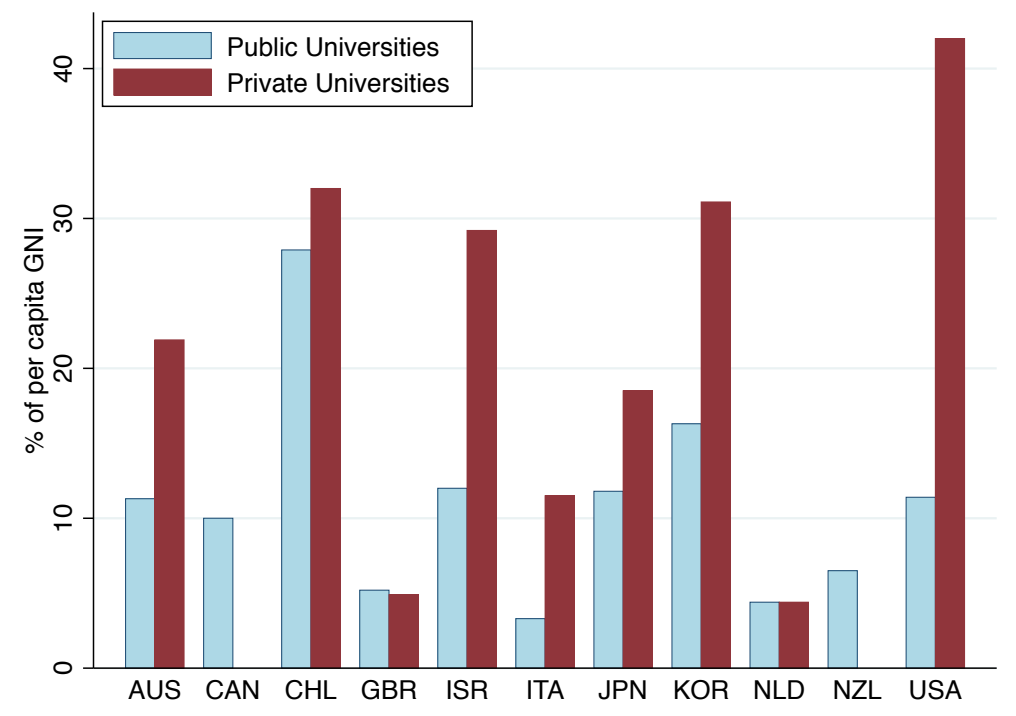

Figure 12: Tuition fees as a percentage of per capita GNI. Source: OECD (2010)

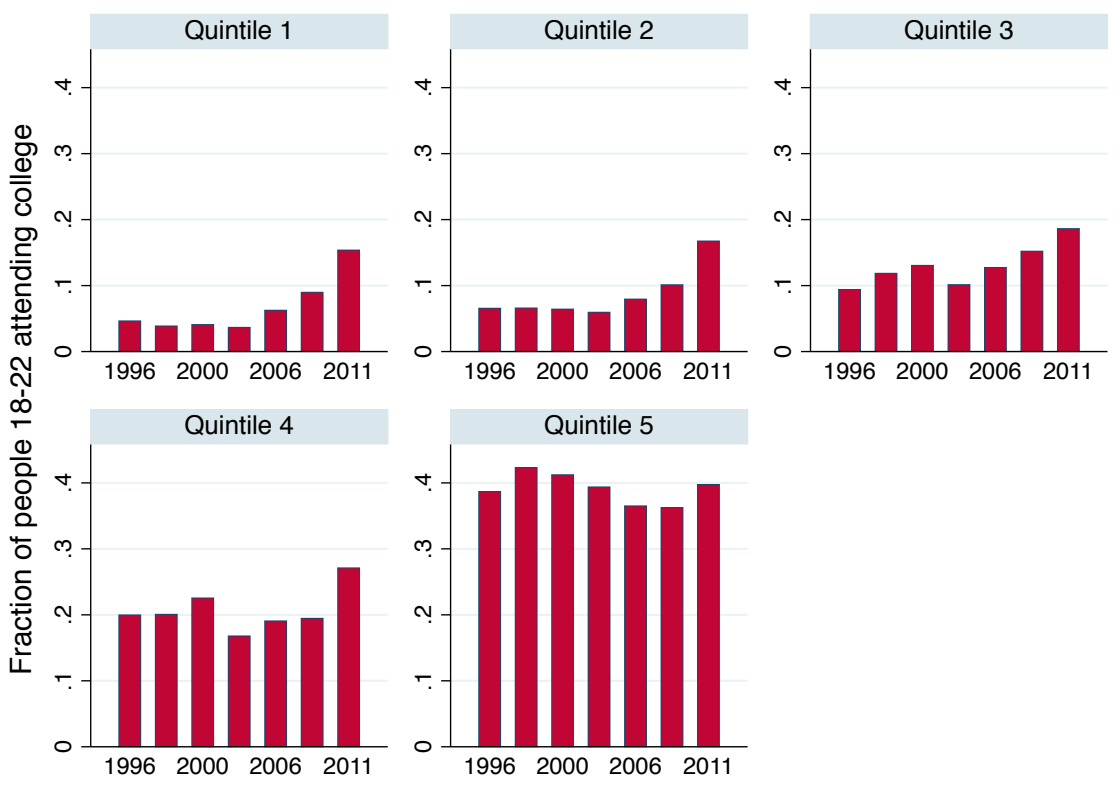

Figure 13: Share of individuals aged 18-22 attending college by quintile of income. Source: CASEN 


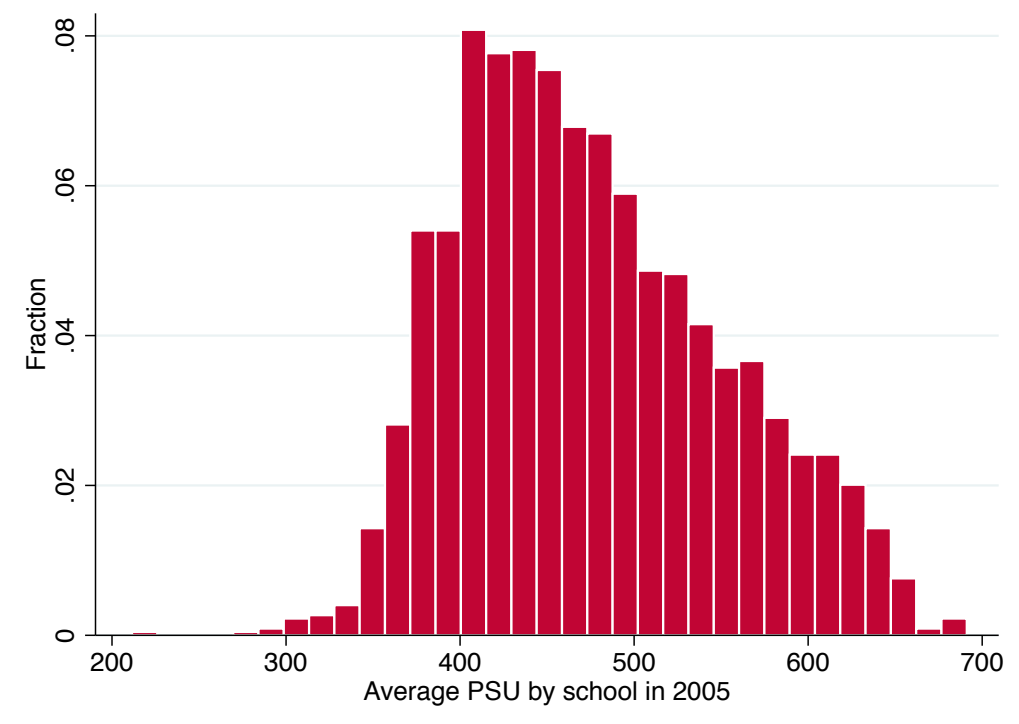

Figure 14: Distribution of average PSU by high school, 2005 


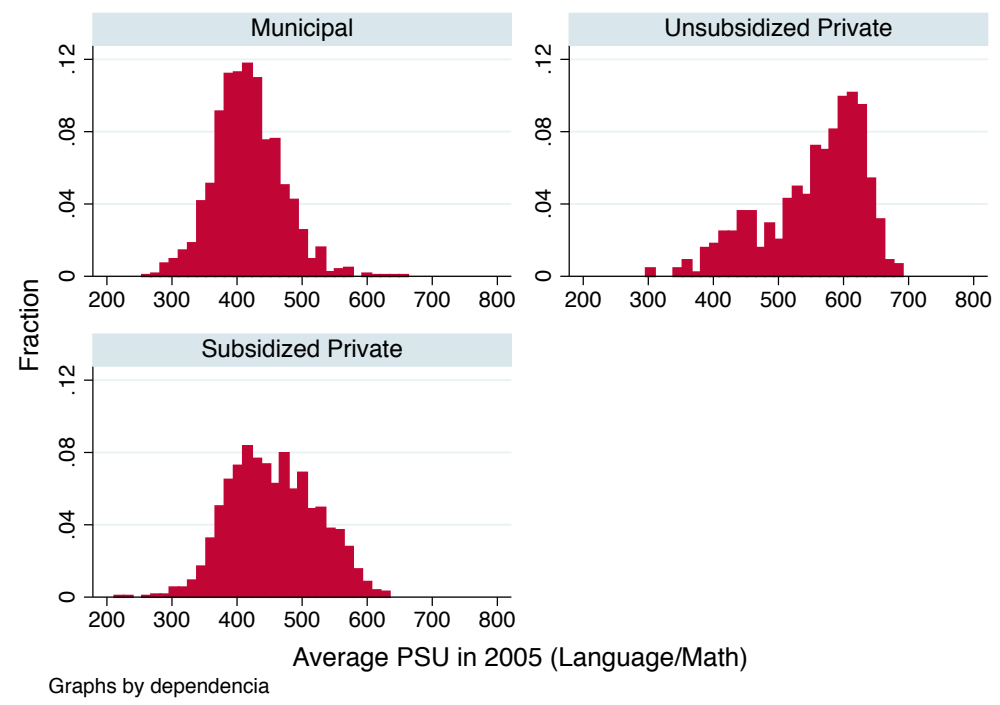

Figure 15: Evolution of PSU scores by type of school

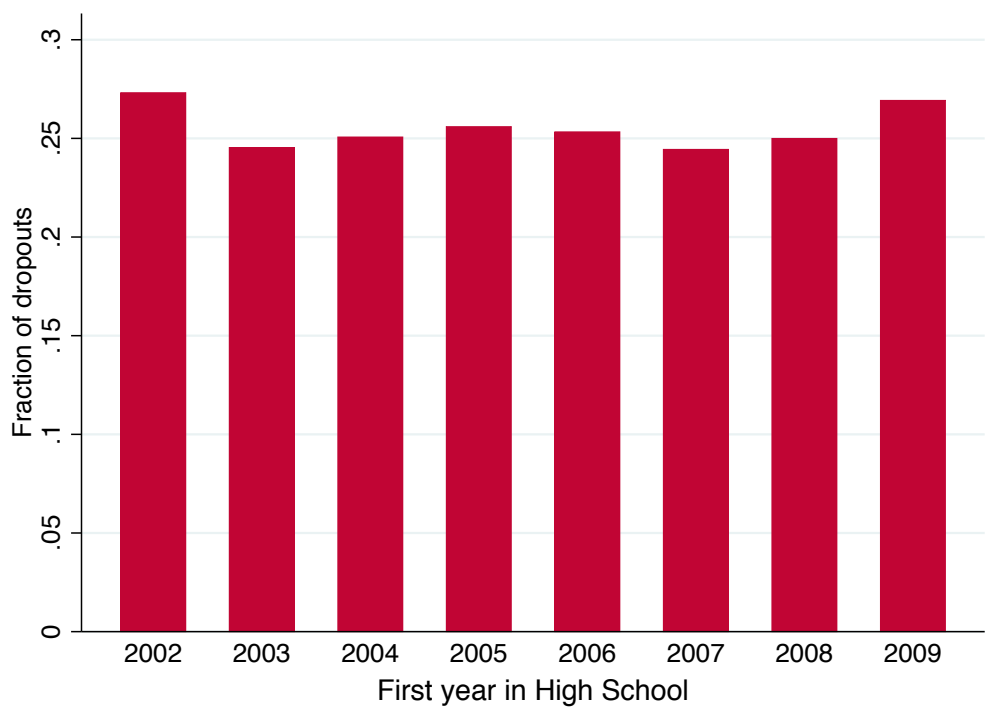

Figure 16: High school dropout by year of entry 
Table 1: Summary Statistics. Students' records 2002-2012

\begin{tabular}{|c|c|c|c|c|c|}
\hline & (1) & $(2)$ & $(3)$ & $(4)$ & $(5)$ \\
\hline VARIABLES & $\mathrm{N}$ & Mean & SD & Min & $\operatorname{Max}$ \\
\hline \multicolumn{6}{|l|}{ Survey of Parents (SIMCE) } \\
\hline Expected college completion & $2,860,717$ & 0.501 & 0.5 & 0 & 1 \\
\hline Year & $2,860,717$ & 2,005 & 2.785 & 2,000 & 2,009 \\
\hline Grade & $2,860,717$ & 6.89 & 2.567 & 4 & 10 \\
\hline School's PSU in 2005 (estimated) & $2,860,717$ & 456.7 & 67.08 & 211.5 & 691.1 \\
\hline Individual SIMCE score & $2,860,717$ & 253.7 & 50 & 97.17 & 419.4 \\
\hline \multicolumn{6}{|l|}{ Students already in High School by 2005} \\
\hline Dropout & $1,044,000$ & 0.23 & 0.42 & 0 & 1 \\
\hline GPA & $3,841,000$ & 5.38 & 0.65 & 1 & 7 \\
\hline Fail & $3,956,000$ & 0.09 & 0.28 & 0 & 1 \\
\hline Change School & $2,912,000$ & 0.18 & 0.38 & 0 & 1 \\
\hline Current School's PSU in 2005 & $3,956,000$ & 463.10 & 66.98 & 211.50 & 691.10 \\
\hline Year & $3,956,000$ & 2005 & 1.64 & 2002 & 2010 \\
\hline Grade & $3,956,000$ & 2.39 & 1.11 & 1 & 4 \\
\hline Sex & $3,956,000$ & 1.50 & 0.50 & 1 & 2 \\
\hline Scientific-Humanistic track & $3,956,000$ & 0.61 & 0.49 & 0 & 1 \\
\hline Age & $3,956,000$ & 16.32 & 1.32 & 14 & 19 \\
\hline Cohort & $3,956,000$ & 1989 & 1.37 & 1984 & 1991 \\
\hline First Year in High School & $3,956,000$ & 2004 & 1.12 & 2002 & 2005 \\
\hline Student's Ranking in first year (percentile) & $3,956,000$ & 52.27 & 28.48 & 0.09 & 100 \\
\hline Original School's PSU in 2005 & $3,956,000$ & 464.80 & 67.19 & 211.5 & 691.1 \\
\hline Years in High School & $3,956,000$ & 2.52 & 1.18 & 1 & 5 \\
\hline \multicolumn{6}{|c|}{ Students in the transition from elementary school } \\
\hline Scientific-Humanistic track & $1,432,000$ & 0.68 & 0.47 & 0 & 1 \\
\hline Current School's PSU in 2005 (estimated) & $5,287,000$ & 454.70 & 67.37 & 211.50 & 691.10 \\
\hline Fail & $5,329,000$ & 0.07 & 0.25 & 0.00 & 1.00 \\
\hline Year & $5,329,000$ & 2004 & 1.74 & 2002 & 2009 \\
\hline Grade & $5,329,000$ & 7.63 & 1.08 & 6.00 & 9.00 \\
\hline Sex & $5,329,000$ & 1.49 & 0.50 & 1.00 & 2.00 \\
\hline Age & $5,329,000$ & 13.51 & 1.32 & 10.00 & 17.00 \\
\hline Cohort & $5,329,000$ & 1991 & 1.77 & 1985 & 1995 \\
\hline Student's GPA ranking (percentile) & $5,210,000$ & 50.96 & 28.80 & 0.10 & 100.00 \\
\hline GPA ranking (tercile) & $5,298,000$ & 2.01 & 0.82 & 1.00 & 3.00 \\
\hline Original School's PSU in 2005 (estimated) & $5,329,000$ & 451.00 & 66.22 & 258.00 & 691.10 \\
\hline Full-day Schooling & $5,329,000$ & 0.52 & 0.50 & 0 & 1 \\
\hline
\end{tabular}


Table 2: Parents' expectation about college completion by school's PSU in 2005

VARIABLES

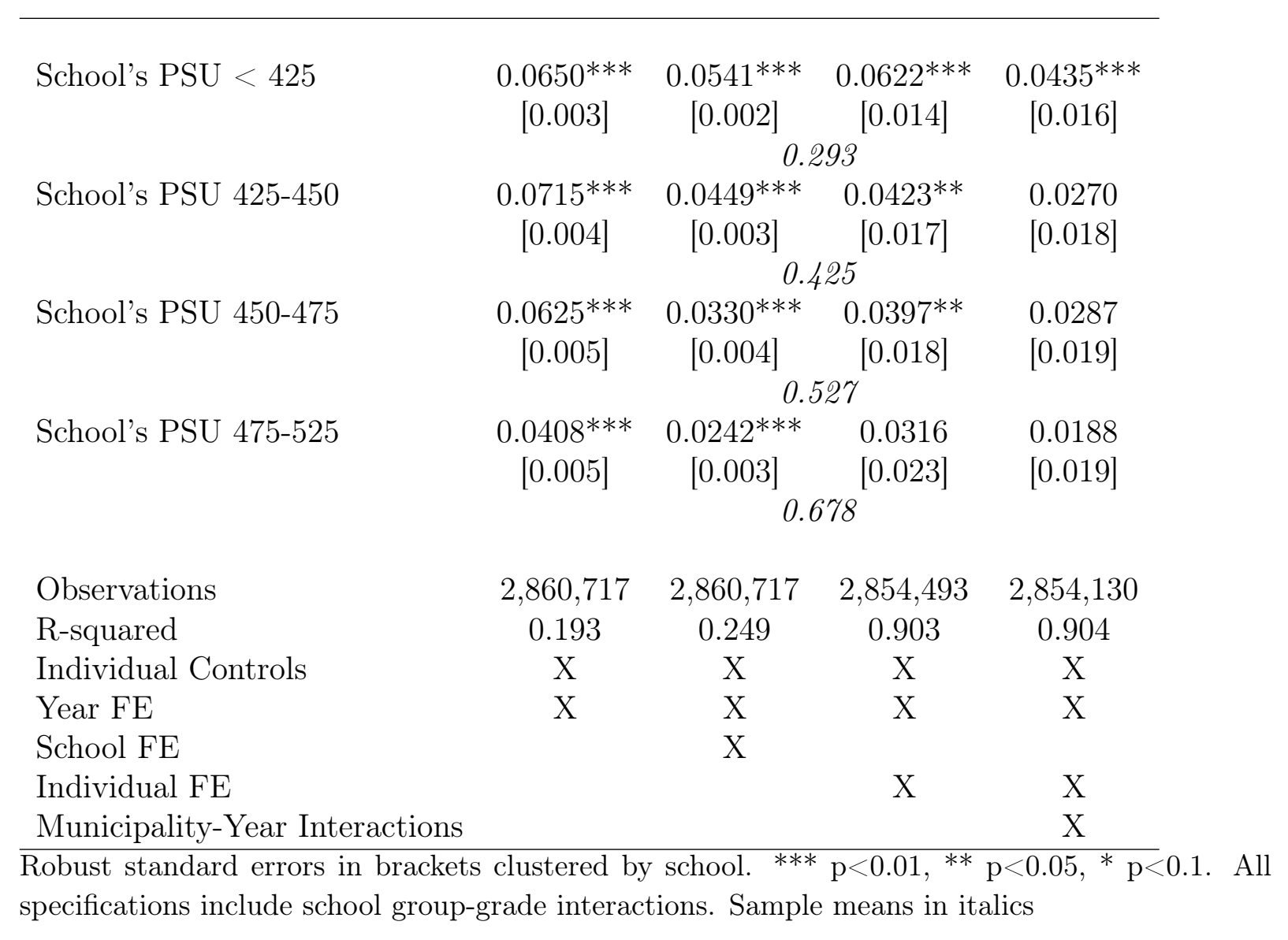


Table 3: Parents' expectation about college completion by school's PSU and ranking VARIABLES

\begin{tabular}{|c|c|c|c|c|}
\hline 1st tercile, school's PSU $<425$ & $\begin{array}{c}0.1244^{* * *} \\
{[0.004]}\end{array}$ & $\begin{array}{c}0.1217^{* * *} \\
{[0.004]}\end{array}$ & $\begin{array}{c}0.1091^{* * *} \\
{[0.006]}\end{array}$ & $\begin{array}{c}0.0961^{* * *} \\
{[0.006]}\end{array}$ \\
\hline & \multicolumn{4}{|c|}{0.409} \\
\hline \multirow[t]{2}{*}{ 2nd tercile, school's PSU $<425$} & $\begin{array}{c}0.0892^{* * *} \\
{[0.004]}\end{array}$ & $\begin{array}{c}0.0896^{* * *} \\
{[0.004]}\end{array}$ & $\begin{array}{c}0.0819^{* * *} \\
{[0.006]}\end{array}$ & $\begin{array}{c}0.0671^{* * *} \\
{[0.006]}\end{array}$ \\
\hline & \multicolumn{4}{|c|}{0.264} \\
\hline \multirow[t]{2}{*}{ 3rd tercile, school's PSU $<425$} & $\begin{array}{c}0.0364^{* * *} \\
{[0.004]}\end{array}$ & $\begin{array}{c}0.0453^{* * *} \\
{[0.004]}\end{array}$ & $\begin{array}{c}0.0514^{* * *} \\
{[0.007]}\end{array}$ & $\begin{array}{c}0.0366^{* * *} \\
{[0.007]}\end{array}$ \\
\hline & \multicolumn{4}{|c|}{0.185} \\
\hline \multirow[t]{2}{*}{ 1st tercile, school's PSU 425-475 } & $\begin{array}{c}0.0807^{* * *} \\
{[0.005]}\end{array}$ & $\begin{array}{c}0.0820^{* * *} \\
{[0.004]}\end{array}$ & $\begin{array}{c}0.0682^{* * *} \\
{[0.007]}\end{array}$ & $\begin{array}{c}0.0614^{* * *} \\
{[0.007]}\end{array}$ \\
\hline & \multicolumn{4}{|c|}{0.612} \\
\hline \multirow[t]{2}{*}{ 2nd tercile, school's PSU 425-475 } & $\begin{array}{c}0.0647^{* * *} \\
{[0.005]}\end{array}$ & $\begin{array}{c}0.0690^{* * *} \\
{[0.004]}\end{array}$ & $\begin{array}{c}0.0617^{* * *} \\
{[0.007]}\end{array}$ & $\begin{array}{c}0.0542^{* * *} \\
{[0.007]}\end{array}$ \\
\hline & \multicolumn{4}{|c|}{0.454} \\
\hline \multirow[t]{2}{*}{ 3rd tercile, school's PSU 425-475 } & $\begin{array}{c}0.0215^{* * *} \\
{[0.005]}\end{array}$ & $\begin{array}{c}0.0368^{* * *} \\
{[0.004]}\end{array}$ & $\begin{array}{c}0.0349^{* * *} \\
{[0.008]}\end{array}$ & $\begin{array}{c}0.0267^{* * *} \\
{[0.007]}\end{array}$ \\
\hline & \multicolumn{4}{|c|}{0.332} \\
\hline \multirow[t]{2}{*}{ 1st tercile, school's PSU 475-525 } & $\begin{array}{c}0.0435^{* * *} \\
{[0.005]}\end{array}$ & $\begin{array}{c}0.0411^{* * *} \\
{[0.005]}\end{array}$ & $\begin{array}{c}0.0327^{* * *} \\
{[0.007]}\end{array}$ & $\begin{array}{c}0.0290^{* * *} \\
{[0.007]}\end{array}$ \\
\hline & \multicolumn{4}{|c|}{0.794} \\
\hline \multirow[t]{2}{*}{ 2nd tercile, school's PSU 475-525 } & $\begin{array}{c}0.0266^{* * *} \\
{[0.006]}\end{array}$ & $\begin{array}{c}0.0272^{* * *} \\
{[0.005]}\end{array}$ & $\begin{array}{c}0.0249^{* * *} \\
{[0.008]}\end{array}$ & $\begin{array}{c}0.0201^{* *} \\
{[0.008]}\end{array}$ \\
\hline & \multicolumn{4}{|c|}{0.677} \\
\hline \multirow[t]{2}{*}{ 3rd tercile, school's PSU 475-525 } & $\begin{array}{c}-0.0058 \\
{[0.006]}\end{array}$ & $\begin{array}{l}0.0012 \\
{[0.005]}\end{array}$ & $\begin{array}{l}0.0022 \\
{[0.009]}\end{array}$ & $\begin{array}{c}-0.0029 \\
{[0.009]}\end{array}$ \\
\hline & \multicolumn{4}{|c|}{0.548} \\
\hline \multirow[t]{2}{*}{ 2nd tercile, school's PSU > 525 } & $\begin{array}{c}-0.0167^{* * *} \\
{[0.003]}\end{array}$ & $\begin{array}{c}-0.0150^{* * *} \\
{[0.003]}\end{array}$ & $\begin{array}{c}-0.0098^{*} \\
{[0.006]}\end{array}$ & $\begin{array}{c}-0.0107^{*} \\
{[0.006]}\end{array}$ \\
\hline & \multicolumn{4}{|c|}{0.886} \\
\hline \multirow[t]{2}{*}{ 3rd tercile, school's PSU $>525$} & $\begin{array}{c}-0.0461^{* * *} \\
{[0.004]}\end{array}$ & $\begin{array}{c}-0.0404^{* * *} \\
{[0.004]}\end{array}$ & $\begin{array}{c}-0.0271^{* * *} \\
{[0.007]}\end{array}$ & $\begin{array}{c}-0.0285^{* * *} \\
{[0.007]}\end{array}$ \\
\hline & \multicolumn{4}{|c|}{0.822} \\
\hline Observations & $1,223,336$ & $1,223,336$ & $1,223,336$ & $1,223,265$ \\
\hline R-squared & 0.253 & 0.298 & 0.814 & 0.815 \\
\hline Individual Controls & $\mathrm{X}$ & $\mathrm{X}$ & $\mathrm{X}$ & $\mathrm{X}$ \\
\hline Year FE & $\mathrm{X}$ & $\mathrm{X}$ & $\mathrm{X}$ & $\mathrm{X}$ \\
\hline School FE & & $\mathrm{X}$ & & \\
\hline Individual Fl & & & $\mathrm{X}$ & $\mathrm{X}$ \\
\hline Municipality-Year Interactions & & & & $\mathrm{X}$ \\
\hline
\end{tabular}

Robust standard errors in brackets clustered by school. ${ }^{* * *} \mathrm{p}<0.01,{ }^{* *} \mathrm{p}<0.05,{ }^{*} \mathrm{p}<0.1$. Sample means in italics 
VARIABLES

(3)

(4)

School's PSU $<425$

$$
\begin{array}{cccc}
-0.0306^{* *} & -0.0310^{* *} & -0.0224^{* *} & -0.0284^{* * *} \\
{[0.012]} & {[0.012]} & {[0.010]} & {[0.010]}
\end{array}
$$

School's PSU 425-450

$$
\begin{array}{cccc}
-0.0368^{* * *} & -0.0357^{* * *} & -0.0216^{* *} & -0.0228^{* *} \\
{[0.012]} & {[0.012]} & {[0.009]} & {[0.009]}
\end{array}
$$

School's PSU 450-475

$$
\begin{array}{llll}
-0.0182 & -0.0190 & -0.0074 & -0.0085 \\
{[0.015]} & {[0.014]} & {[0.010]} & {[0.009]}
\end{array}
$$

School's PSU 475-525

$$
\begin{array}{cccc}
-0.0271^{* *} & -0.0262^{* *} & -0.0190^{* *} & -0.0126 \\
{[0.011]} & {[0.011]} & {[0.008]} & {[0.008]} \\
& \multicolumn{2}{c}{0.154} &
\end{array}
$$

Observations

R-squared

Individual Controls

Year FE

Municipality FE

School FE

Municipality-Year Interactions

$$
\begin{gathered}
1,046,342 \\
0.366 \\
\mathrm{X}
\end{gathered}
$$$$
1,046,258
$$$$
1,046,342
$$$$
1,046,258
$$$$
0.373
$$$$
\mathrm{X}
$$$$
\mathrm{X}
$$$$
0.407
$$$$
0.416
$$$$
\mathrm{X}
$$$$
\mathrm{X}
$$$$
\mathrm{X}
$$$$
\mathrm{X}
$$$$
\mathrm{X}
$$$$
\mathrm{X}
$$$$
\text { X }
$$

$\mathrm{X}$

Robust standard errors in brackets clustered by school. ${ }^{* * *} \mathrm{p}<0.01,{ }^{* *} \mathrm{p}<0.05,{ }^{*} \mathrm{p}<0.1$. Sample means in italics 
Table 5: Dropout by school's PSU in 2005 and ranking in first year

VARIABLES (1) (2) (3)

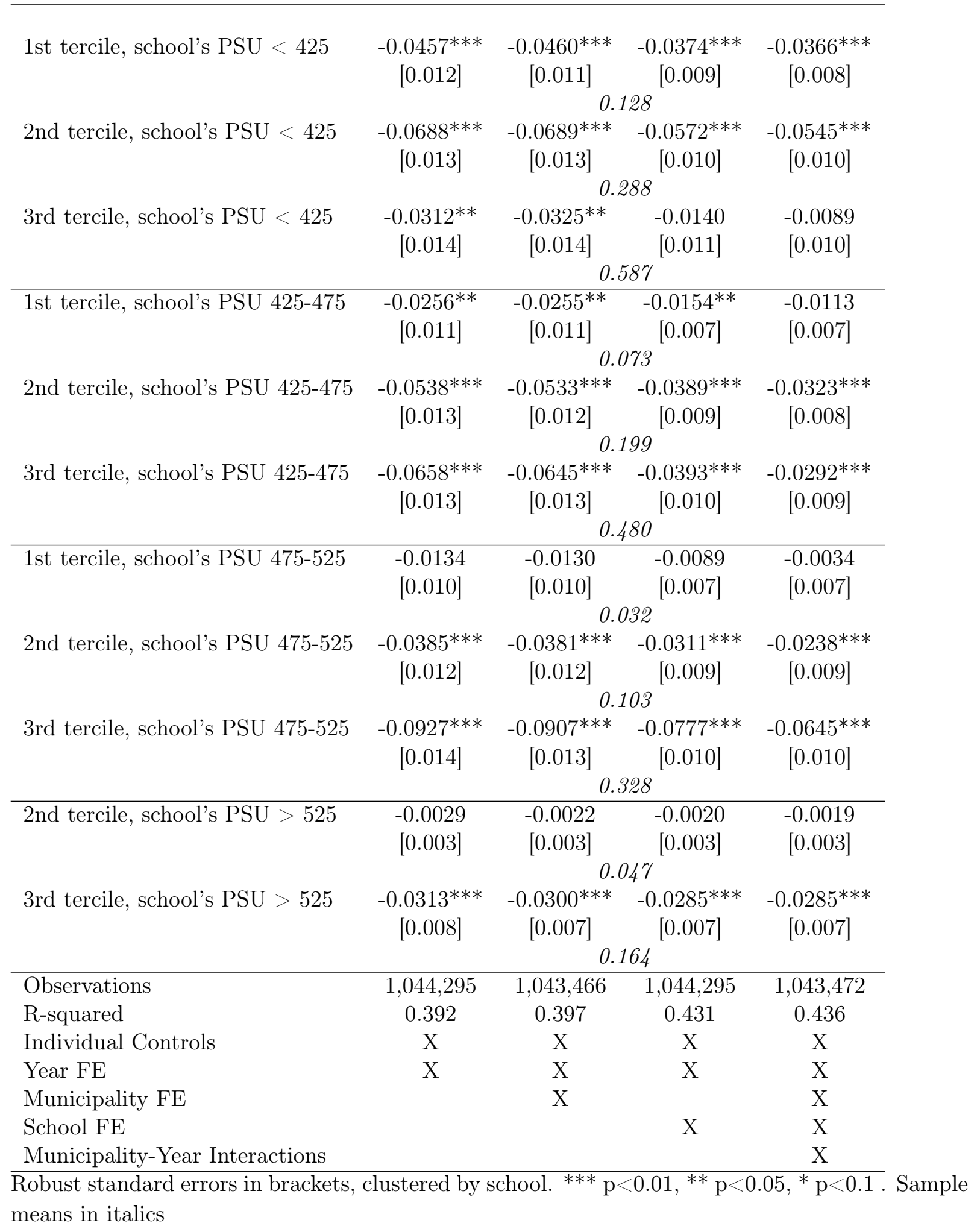



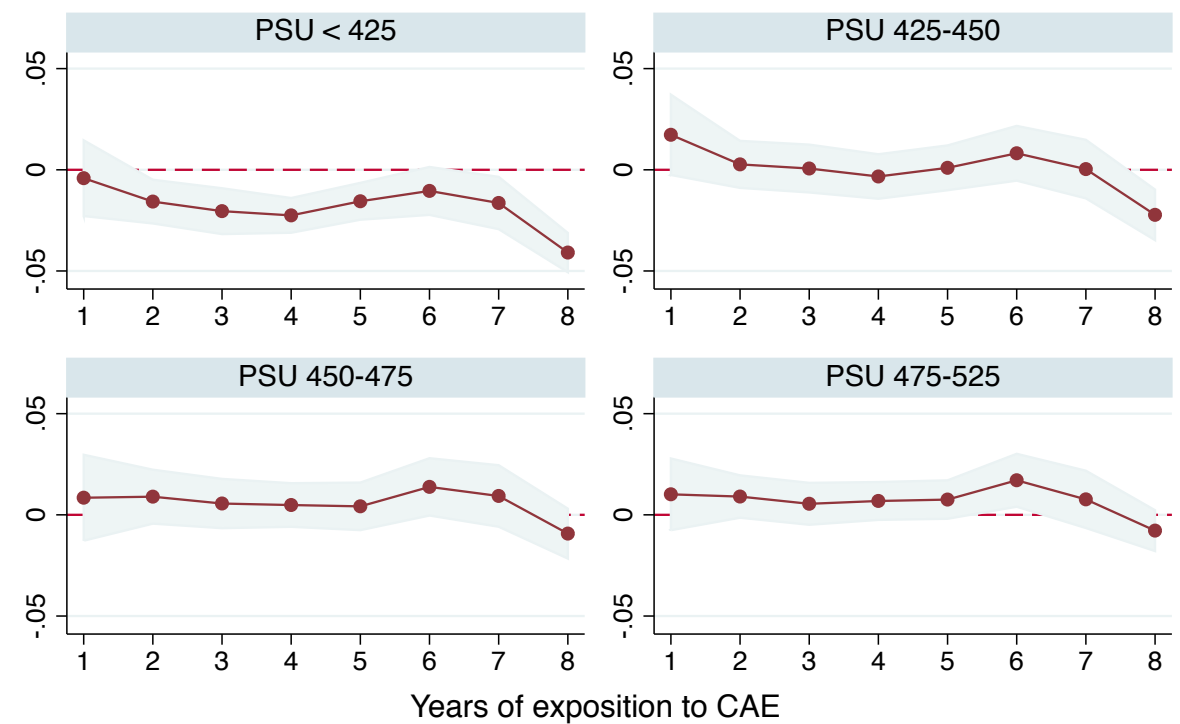

$\longrightarrow$ Regression Coefficient

95\% Confidence Interval

Note: Specification includes year and school fixed effects.

Figure 17: Dropout by school's PSU in 2005 and exposure to the reform 
Table 6: Academic performance by school's PSU in 2005

\begin{tabular}{|c|c|c|c|c|}
\hline \multirow[b]{2}{*}{ VARIABLES } & \multicolumn{2}{|c|}{$G P A$} & \multicolumn{2}{|c|}{ Fail } \\
\hline & (1) & $(2)$ & (3) & (4) \\
\hline \multirow[t]{2}{*}{ School's PSU $<425$} & $\begin{array}{c}-0.0821^{* * *} \\
{[0.011]}\end{array}$ & $\begin{array}{c}-0.0653^{* * *} \\
{[0.012]}\end{array}$ & $\begin{array}{c}0.0185^{* * *} \\
{[0.003]}\end{array}$ & $\begin{array}{c}0.0160^{* * *} \\
{[0.003]}\end{array}$ \\
\hline & \multicolumn{2}{|c|}{5.212} & \multicolumn{2}{|c|}{0.098} \\
\hline \multirow[t]{2}{*}{ School's PSU 425-450 } & $\begin{array}{c}-0.0771^{* * *} \\
{[0.012]}\end{array}$ & $\begin{array}{c}-0.0540 * * * \\
{[0.013]}\end{array}$ & $\begin{array}{c}0.0103^{* * *} \\
{[0.003]}\end{array}$ & $\begin{array}{c}0.0093^{* * *} \\
{[0.003]}\end{array}$ \\
\hline & \multicolumn{2}{|c|}{5.260} & \multicolumn{2}{|c|}{0.092} \\
\hline \multirow[t]{2}{*}{ School's PSU 450-475 } & $\begin{array}{c}-0.0796^{* * *} \\
{[0.012]}\end{array}$ & $\begin{array}{c}-0.0642^{* * *} \\
{[0.012]}\end{array}$ & $\begin{array}{c}0.0094^{* * *} \\
{[0.003]}\end{array}$ & $\begin{array}{c}0.0073^{* *} \\
{[0.003]}\end{array}$ \\
\hline & \multicolumn{2}{|c|}{5.337} & \multicolumn{2}{|c|}{0.082} \\
\hline \multirow[t]{2}{*}{ School's PSU 475-525 } & $\begin{array}{c}-0.0570^{* * *} \\
{[0.012]}\end{array}$ & $\begin{array}{c}-0.0447 * * * \\
{[0.011]}\end{array}$ & $\begin{array}{c}0.0062^{* *} \\
{[0.003]}\end{array}$ & $\begin{array}{l}0.0040 \\
{[0.003]}\end{array}$ \\
\hline & \multicolumn{2}{|c|}{5.465} & \multicolumn{2}{|c|}{0.066} \\
\hline Observations & $3,828,554$ & $3,828,457$ & $3,945,201$ & $3,945,099$ \\
\hline R-squared & 0.813 & 0.819 & 0.425 & 0.429 \\
\hline Individual Controls & $\mathrm{X}$ & $\mathrm{X}$ & $\mathrm{X}$ & $\mathrm{X}$ \\
\hline Year FE & $\mathrm{X}$ & $\mathrm{X}$ & $\mathrm{X}$ & $\mathrm{X}$ \\
\hline Municipality FE & $\mathrm{X}$ & & & \\
\hline Individual FE & $\mathrm{X}$ & $\mathrm{X}$ & $\mathrm{X}$ & $\mathrm{X}$ \\
\hline Municipality-Year Interactions & & $\mathrm{X}$ & & $\mathrm{X}$ \\
\hline
\end{tabular}

Robust standard errors in brackets clustered by school. All specifications include school group -time in school interactions. ${ }^{* * *} \mathrm{p}<0.01,{ }^{* *} \mathrm{p}<0.05,{ }^{*} \mathrm{p}<0.1$ 
Table 7: Academic performance, by school's PSU in 2005 and ranking in first year

\begin{tabular}{|c|c|c|}
\hline \multirow[b]{2}{*}{ VARIABLES } & GPA & Fail \\
\hline & (2) & (4) \\
\hline \multirow[t]{2}{*}{ 1st tercile, school's PSU $<425$} & $\begin{array}{cc}-0.0620^{* * *} & -0.0626^{* * *} \\
{[0.008]} & {[0.009]}\end{array}$ & $\begin{array}{cc}0.0089^{* *} & 0.0115^{* * *} \\
{[0.004]} & {[0.004]}\end{array}$ \\
\hline & 5.66 & 0.023 \\
\hline \multirow[t]{2}{*}{ 2nd tercile, school's PSU $<425$} & $\begin{array}{cc}0.0880^{* * *} & 0.0857^{* * *} \\
{[0.009]} & {[0.009]}\end{array}$ & $\begin{array}{cc}0.0354^{* * *} & 0.0387^{* * *} \\
{[0.004]} & {[0.004]}\end{array}$ \\
\hline & 5.13 & 0.075 \\
\hline \multirow[t]{2}{*}{ 3rd tercile, school's PSU $<425$} & $\begin{array}{cc}0.2568^{* * *} & 0.2542^{* * *} \\
{[0.010]} & {[0.010]}\end{array}$ & $\begin{array}{cc}-0.0922^{* * *} & -0.0888^{* * *} \\
{[0.006]} & {[0.006]}\end{array}$ \\
\hline & 4.73 & 0.253 \\
\hline \multirow[t]{2}{*}{ 1st tercile, school's PSU 425-475 } & $\begin{array}{cc}-0.0407 * * * & -0.0409^{* * *} \\
{[0.009]} & {[0.009]}\end{array}$ & $\begin{array}{ll}0.0064 & 0.0086^{*} \\
{[0.004]} & {[0.005]}\end{array}$ \\
\hline & 5.77 & 0.016 \\
\hline \multirow[t]{2}{*}{ 2nd tercile, school's PSU 425-475 } & $\begin{array}{cc}0.0768^{* * *} & 0.0757^{* * *} \\
{[0.009]} & {[0.009]}\end{array}$ & $\begin{array}{cc}0.0322^{* * *} & 0.0349^{* * *} \\
{[0.004]} & {[0.005]}\end{array}$ \\
\hline & 5.22 & 0.062 \\
\hline \multirow[t]{2}{*}{ 3rd tercile, school's PSU 425-475 } & $\begin{array}{cc}0.2513^{* * *} & 0.2498^{* * *} \\
{[0.009]} & {[0.009]}\end{array}$ & $\begin{array}{cc}-0.0876^{* * *} & -0.0847^{* * *} \\
{[0.006]} & {[0.006]}\end{array}$ \\
\hline & 4.83 & 0.222 \\
\hline \multirow[t]{2}{*}{ 1st tercile, school's PSU 475-525 } & $\begin{array}{cc}-0.0113 & -0.0122 \\
{[0.009]} & {[0.009]}\end{array}$ & $\begin{array}{cc}-0.0030 & -0.0002 \\
{[0.005]} & {[0.005]}\end{array}$ \\
\hline & 5.97 & 0.007 \\
\hline \multirow[t]{2}{*}{ 2nd tercile, school's PSU 475-525 } & $\begin{array}{cc}0.0700^{* * *} & 0.0691 * * * \\
{[0.009]} & {[0.009]}\end{array}$ & $\begin{array}{cc}0.0160^{* * *} & 0.0189^{* * *} \\
{[0.005]} & {[0.005]}\end{array}$ \\
\hline & 5.41 & 0.038 \\
\hline \multirow[t]{2}{*}{ 3rd tercile, school's PSU 475-525 } & $\begin{array}{cc}0.2295^{* * *} & 0.2276^{* * *} \\
{[0.011]} & {[0.010]}\end{array}$ & $\begin{array}{cc}-0.0721^{* * * *} & -0.0688^{* * *} \\
{[0.006]} & {[0.006]}\end{array}$ \\
\hline & 5.01 & 0.170 \\
\hline \multirow[t]{2}{*}{ 2nd tercile, school's PSU > 525} & $\begin{array}{cc}0.0746^{* * *} & 0.0745^{* * *} \\
{[0.005]} & {[0.005]}\end{array}$ & $\begin{array}{cc}0.0076^{* * *} & 0.0077^{* * *} \\
{[0.001]} & {[0.001]}\end{array}$ \\
\hline & 5.31 & 0.020 \\
\hline 3rd tercile, school's PSU $>525$ & $\begin{array}{cc}0.2179^{* * *} & 0.2162^{* * *} \\
{[0.008]} & {[0.008]}\end{array}$ & $\begin{array}{cc}-0.0598^{* * *} & -0.0590^{* * *} \\
{[0.005]} & {[0.005]}\end{array}$ \\
\hline & 4.92 & 0.109 \\
\hline Observations & $3,840,114$ & $3,956,286$ \\
\hline R-squared & 0.819 & 0.432 \\
\hline Year FE & $\mathrm{X}$ & $\mathrm{X}$ \\
\hline Municipality FE & $\mathrm{X}$ & $\mathrm{X}$ \\
\hline Individual $\mathrm{FE}$ & $\mathrm{X}$ & $\mathrm{X}$ \\
\hline Municipality-Year Interactions & $\mathrm{x}$ & $\mathrm{X}$ \\
\hline
\end{tabular}


Table 8: School switching by school's PSU in 2005 and ranking in first year

\begin{tabular}{|c|c|c|c|}
\hline \multirow{3}{*}{$\begin{array}{l}\text { VARIABLES } \\
\text { 1st tercile, school's PSU }<425\end{array}$} & (1) & (3) & (4) \\
\hline & Change School & \multicolumn{2}{|c|}{ PSU in 2005 (Current School } \\
\hline & $\begin{array}{cc}0.0388^{* * *} & 0.0395^{* * * *} \\
{[0.006]} & {[0.006]}\end{array}$ & $\begin{array}{c}7.2545^{* * *} \\
{[0.322]}\end{array}$ & $\begin{array}{c}9.1416^{* * *} \\
{[0.379]}\end{array}$ \\
\hline & 0.178 & \multicolumn{2}{|c|}{402.70} \\
\hline \multirow[t]{2}{*}{ 2nd tercile, school's PSU $<425$} & $\begin{array}{cc}0.0513^{* * *} & 0.0523^{* * *} \\
{[0.006]} & {[0.006]}\end{array}$ & $\begin{array}{c}5.3346^{* * *} \\
{[0.283]}\end{array}$ & $\begin{array}{c}7.1925^{* * *} \\
{[0.354]}\end{array}$ \\
\hline & 0.177 & \multicolumn{2}{|c|}{400.68} \\
\hline \multirow[t]{2}{*}{ 3rd tercile, school's PSU $<425$} & $\begin{array}{cc}0.0727^{* * * *} & 0.0736^{* * *} \\
{[0.006]} & {[0.006]}\end{array}$ & $\begin{array}{c}5.4924^{* * *} \\
{[0.340]}\end{array}$ & $\begin{array}{c}7.3061^{* * *} \\
{[0.393]}\end{array}$ \\
\hline & 0.255 & \multicolumn{2}{|c|}{400.43} \\
\hline \multirow[t]{2}{*}{ 1st tercile, school's PSU 425-475 } & $\begin{array}{cc}0.0210^{* * *} & 0.0214^{* * *} \\
{[0.004]} & {[0.004]}\end{array}$ & $\begin{array}{c}2.3744^{* * *} \\
{[0.250]}\end{array}$ & $\begin{array}{c}3.2849^{* * *} \\
{[0.306]}\end{array}$ \\
\hline & 0.128 & \multicolumn{2}{|c|}{449.43} \\
\hline \multirow[t]{2}{*}{ 2nd tercile, school's PSU 425-475 } & $\begin{array}{cc}0.0448^{* * * *} & 0.0452^{* * *} \\
{[0.005]} & {[0.005]}\end{array}$ & $\begin{array}{c}-0.4194 \\
{[0.270]}\end{array}$ & $\begin{array}{l}0.4650 \\
{[0.311]}\end{array}$ \\
\hline & 0.153 & \multicolumn{2}{|c|}{447.14} \\
\hline \multirow[t]{2}{*}{ 3rd tercile, school's PSU 425-475 } & $\begin{array}{cc}0.0805^{* * *} & 0.0804^{* * *} \\
{[0.005]} & {[0.005]}\end{array}$ & $\begin{array}{c}-3.8237 * * * \\
{[0.366]}\end{array}$ & $\begin{array}{c}-2.9235^{* * *} \\
{[0.376]}\end{array}$ \\
\hline & 0.264 & \multicolumn{2}{|c|}{$443.65^{\circ}$} \\
\hline \multirow[t]{2}{*}{ 1st tercile, school's PSU 475-525 } & $\begin{array}{cc}0.0116^{* *} & 0.0156^{* * *} \\
{[0.005]} & {[0.006]}\end{array}$ & $\begin{array}{c}1.1952^{* * *} \\
{[0.275]}\end{array}$ & $\begin{array}{c}1.6623^{* * *} \\
{[0.346]}\end{array}$ \\
\hline & 0.100 & \multicolumn{2}{|c|}{496.22} \\
\hline \multirow[t]{2}{*}{ 2nd tercile, school's PSU 475-525 } & $\begin{array}{cc}0.0404^{* * *} & 0.0442^{* * *} \\
{[0.006]} & {[0.006]}\end{array}$ & $\begin{array}{c}-2.9953 * * * \\
{[0.377]}\end{array}$ & $\begin{array}{c}-2.5411^{* * *} \\
{[0.385]}\end{array}$ \\
\hline & 0.134 & \multicolumn{2}{|c|}{493.09} \\
\hline \multirow[t]{2}{*}{ 3rd tercile, school's PSU 475-525 } & $\begin{array}{cc}0.0902^{* * *} & 0.0937^{* * *} \\
{[0.007]} & {[0.006]}\end{array}$ & $\begin{array}{c}-11.2773^{* * *} \\
{[0.574]}\end{array}$ & $\begin{array}{c}-10.7967^{* * *} \\
{[0.538]}\end{array}$ \\
\hline & 0.265 & \multicolumn{2}{|c|}{485.39} \\
\hline \multirow[t]{2}{*}{ 2nd tercile, school's PSU $>525$} & $\begin{array}{cc}0.0246^{* * *} & 0.0245^{* * *} \\
{[0.003]} & {[0.003]}\end{array}$ & $\begin{array}{c}-4.0541^{* * *} \\
{[0.309]}\end{array}$ & $\begin{array}{c}-4.0113^{* * *} \\
{[0.305]}\end{array}$ \\
\hline & 0.100 & \multicolumn{2}{|c|}{573.77} \\
\hline 3rd tercile, school's PSU $>525$ & $\begin{array}{cc}0.0897^{* * *} & 0.0894^{* * *} \\
{[0.005]} & {[0.005]}\end{array}$ & $\begin{array}{c}-18.2113^{* * *} \\
{[0.704]}\end{array}$ & $\begin{array}{c}-18.0931^{* * *} \\
{[0.694]}\end{array}$ \\
\hline & 0.247 & & \\
\hline Observations & $2,911,742 \quad 2,911,727$ & $3,956,286$ & $3,955,405$ \\
\hline R-squared & 0.825 & 0.957 & 0.957 \\
\hline Year FE & $\mathrm{X}$ & $\mathrm{X}$ & $\mathrm{X}$ \\
\hline Municipality FE & $\mathrm{X}$ & $\mathrm{X}$ & $\mathrm{X}$ \\
\hline Individual FE & $\mathrm{X}$ & $\mathrm{X}$ & $\mathrm{X}$ \\
\hline Municipality-Year Interactions & $\mathrm{X}$ & & $\mathrm{X}$ \\
\hline
\end{tabular}


Table 9: Scientific-Humanistic track by (estimated) school's PSU and ranking in 6th grade

\begin{tabular}{|c|c|c|c|c|}
\hline \multirow[t]{2}{*}{ VARIABLES } & \multicolumn{3}{|c|}{ All Schools } & Only primary \\
\hline & (1) & $(2)$ & (3) & $(4) \quad(5)$ \\
\hline \multirow[t]{2}{*}{ 1st tercile, school's PSU $<425$} & $\begin{array}{c}0.0421^{* * *} \\
{[0.005]}\end{array}$ & $\begin{array}{c}0.0378^{* * *} \\
{[0.004]}\end{array}$ & $\begin{array}{c}0.0351^{* * *} \\
{[0.004]}\end{array}$ & $\begin{array}{cc}-0.0007 & -0.0068 \\
{[0.008]} & {[0.008]}\end{array}$ \\
\hline & & 0.561 & & 0.536 \\
\hline 2nd tercile, school's PSU $<425$ & $\begin{array}{c}0.0145^{* * *} \\
{[0.005]}\end{array}$ & $\begin{array}{c}0.0106^{* * *} \\
{[0.004]} \\
0.558\end{array}$ & $\begin{array}{c}0.0089^{* *} \\
{[0.004]}\end{array}$ & $\begin{array}{cc}-0.0191^{* * *} & -0.0232^{* * *} \\
{[0.007]} & {[0.008]} \\
0.529 & \end{array}$ \\
\hline 3rd tercile, school's PSU $<425$ & $\begin{array}{r}-0.0016 \\
{[0.005]}\end{array}$ & $\begin{array}{c}-0.0048 \\
{[0.004]} \\
0.586\end{array}$ & $\begin{array}{l}-0.0065 \\
{[0.005]}\end{array}$ & $\begin{array}{cc}-0.0320^{* * *} & -0.0348^{* * *} \\
{[0.008]} & {[0.008]} \\
0.559 & \end{array}$ \\
\hline 1st tercile, school's PSU 425-475 & $\begin{array}{c}0.0398^{* * *} \\
{[0.005]}\end{array}$ & $\begin{array}{c}0.0354^{* * *} \\
{[0.004]} \\
0.684\end{array}$ & $\begin{array}{c}0.0318^{* * *} \\
{[0.005]}\end{array}$ & $\begin{array}{cc}0.0259^{* * *} & 0.0216^{* * *} \\
{[0.008]} & {[0.008]} \\
0.640 & \end{array}$ \\
\hline 2nd tercile, school's PSU $425-475$ & $\begin{array}{c}0.0186^{* * *} \\
{[0.006]}\end{array}$ & $\begin{array}{c}0.0121^{* * *} \\
{[0.005]} \\
0.621\end{array}$ & $\begin{array}{l}0.0092^{*} \\
{[0.005]}\end{array}$ & $\begin{array}{cc}-0.0197^{* *} & -0.0223^{* * *} \\
{[0.008]} & {[0.008]}\end{array}$ \\
\hline 3rd tercile, school's PSU 425-475 & $\begin{array}{l}0.0004 \\
{[0.006]}\end{array}$ & $\begin{array}{c}-0.0057 \\
{[0.005]} \\
0.622\end{array}$ & $\begin{array}{c}-0.0090^{*} \\
{[0.005]}\end{array}$ & $\begin{array}{cc}-0.0412^{* * *} & -0.0421^{* * *} \\
{[0.008]} & {[0.008]}\end{array}$ \\
\hline 1st tercile, school's PSU $475-525$ & $\begin{array}{c}0.0258^{* * *} \\
{[0.005]}\end{array}$ & $\begin{array}{c}0.0210^{* * *} \\
{[0.004]} \\
0.865\end{array}$ & $\begin{array}{c}0.0165^{* * *} \\
{[0.005]}\end{array}$ & $\begin{array}{cc}0.0191^{* * *} & 0.0143^{*} \\
{[0.007]} & {[0.008]}\end{array}$ \\
\hline 2nd tercile, school's PSU 475-525 & $\begin{array}{c}0.0271^{* * *} \\
{[0.006]}\end{array}$ & $\begin{array}{c}0.0205^{* * *} \\
{[0.005]} \\
0.798\end{array}$ & $\begin{array}{c}0.0162^{* * *} \\
{[0.005]}\end{array}$ & $\begin{array}{cc}-0.0122^{*} & -0.0162^{* *} \\
0.007] & {[0.008]}\end{array}$ \\
\hline 3rd tercile, school's PSU 475-525 & $\begin{array}{l}0.0008 \\
{[0.007]}\end{array}$ & $\begin{array}{c}-0.0045 \\
{[0.006]} \\
0.753\end{array}$ & $\begin{array}{r}-0.0081 \\
{[0.006]}\end{array}$ & $\begin{array}{cc}-0.0348^{* * *} & -0.0387^{* * *} \\
{[0.008]} & {[0.008]} \\
0.643 & \end{array}$ \\
\hline 2nd tercile, school's PSU > 525 & $\begin{array}{l}-0.0003 \\
{[0.002]}\end{array}$ & $\begin{array}{c}-0.0004 \\
{[0.002]} \\
0.956\end{array}$ & $\begin{array}{c}-0.0005 \\
{[0.002]}\end{array}$ & {$[0.0100 \quad 0.0064$} \\
\hline 3rd tercile, school's PSU $>525$ & $\begin{array}{c}-0.0097^{* * *} \\
{[0.003]}\end{array}$ & $\begin{array}{c}-0.0104^{* * *} \\
{[0.002]} \\
0.937\end{array}$ & $\begin{array}{c}-0.0100^{* * *} \\
{[0.002]}\end{array}$ & $\begin{array}{cc}-0.0258^{* * *} & -0.0273^{* * *} \\
{[0.010]} & {[0.010]} \\
0.771\end{array}$ \\
\hline Observations & $1,433,994$ & $1,433,994$ & $1,428,594$ & 847,126 \\
\hline R-squared & 0.100 & 0.250 & 0.260 & 0.146 \\
\hline Individual Controls & $\mathrm{X}$ & $\mathrm{X}$ & $\mathrm{X}$ & $\mathrm{X}$ \\
\hline Year FE & $\mathrm{X}$ & $\mathrm{X}$ & $\mathrm{X}$ & $\mathrm{X}$ \\
\hline Municipality FE & & & $\mathrm{X}$ & $\mathrm{X}$ \\
\hline School FE & & $\mathrm{X}$ & $\mathrm{x}$ & $\mathrm{X}$ \\
\hline Municipality-Year Interactions & & & $\mathrm{X}$ & $\mathrm{X}$ \\
\hline
\end{tabular}

Robust standard errors in brackets clustered by school. ${ }^{* * *} \mathrm{p}<0.01,{ }^{* *} \mathrm{p}<0.05,{ }^{*} \mathrm{p}<0.1$. Sample means in italics 
Table 10: Current school's PSU by (estimated) school's PSU and ranking in 6th grade

\begin{tabular}{|c|c|c|c|c|c|}
\hline \multirow[t]{2}{*}{ VARIABLES } & \multicolumn{3}{|c|}{ All Schools } & \multicolumn{2}{|c|}{ Only primary } \\
\hline & (1) & (2) & (3) & & (5) \\
\hline \multirow[t]{2}{*}{ 1st tercile, school's PSU $<425$} & $\begin{array}{c}15.9696^{* * *} \\
{[0.954]}\end{array}$ & $\begin{array}{c}28.9555^{* * *} \\
{[0.652]}\end{array}$ & $\begin{array}{c}31.9877^{* * *} \\
{[0.735]}\end{array}$ & $\begin{array}{c}33.8325^{* * *} \\
{[2.430]}\end{array}$ & $\begin{array}{c}36.9310^{* * * *} \\
{[2.251]}\end{array}$ \\
\hline & & 411.77 & & \multicolumn{2}{|c|}{413.31} \\
\hline 2nd tercile, school's PSU $<425$ & $\begin{array}{c}8.8274^{* * *} \\
{[0.948]}\end{array}$ & $\begin{array}{c}15.9745^{* * *} \\
{[0.621]} \\
404.47\end{array}$ & $\begin{array}{c}19.8058^{* * *} \\
{[0.712]}\end{array}$ & $\begin{array}{c}22.2593^{* * *} \\
{[2.420]}\end{array}$ & $\begin{array}{c}26.0454^{* * *} \\
{[2.237]} \\
75\end{array}$ \\
\hline 3rd tercile, school's PSU $<425$ & $\begin{array}{c}6.0044^{* * *} \\
{[0.958]}\end{array}$ & $\begin{array}{c}10.0551^{* * *} \\
{[0.602]} \\
401.16\end{array}$ & $\begin{array}{c}16.6243^{* * *} \\
{[0.703]}\end{array}$ & $\begin{array}{c}15.7351^{* * *} \\
{[2.419]}\end{array}$ & $\begin{array}{c}22.0189^{* * *} \\
\quad[2.236] \\
58\end{array}$ \\
\hline 1st tercile, school's PSU $425-475$ & $\begin{array}{c}9.9280^{* * *} \\
{[0.988]}\end{array}$ & $\begin{array}{c}16.2118^{* * *} \\
{[0.759]} \\
457.32\end{array}$ & $\begin{array}{c}18.4879^{* * *} \\
{[0.789]}\end{array}$ & $\begin{array}{c}22.4584^{* * *} \\
{[2.444]}\end{array}$ & $\begin{array}{c}24.3241^{* * *} \\
28 \\
22.242]\end{array}$ \\
\hline 2nd tercile, school's PSU 425-475 & $\begin{array}{l}0.4869 \\
{[0.957]}\end{array}$ & $\begin{array}{l}0.2195 \\
{[0.674]} \\
447.60\end{array}$ & $\begin{array}{c}2.9765^{* * *} \\
{[0.705]}\end{array}$ & $\begin{array}{c}8.8259^{* * *} \\
{[2.425]} \\
446\end{array}$ & $\begin{array}{c}11.3727^{* * *} \\
{ }_{47}^{[2.230]}\end{array}$ \\
\hline 3rd tercile, school's PSU 425-475 & $\begin{array}{c}-4.7873^{* * *} \\
{[0.963]}\end{array}$ & $\begin{array}{c}-8.0692^{* * *} \\
{[0.659]} \\
442.12\end{array}$ & $\begin{array}{c}-2.7478^{* * *} \\
{[0.702]}\end{array}$ & $\begin{array}{l}2.6710 \\
{[2.426]} \\
\quad 440\end{array}$ & $\begin{array}{c}7.8105^{* * * *} \\
{ }_{53}[2.232]\end{array}$ \\
\hline 1st tercile, school's PSU $475-525$ & $\begin{array}{c}7.4746^{* * *} \\
{[1.060]}\end{array}$ & $\begin{array}{c}8.9501^{* * *} \\
{[0.891]} \\
502.97\end{array}$ & $\begin{array}{c}10.4984^{* * *} \\
{[0.914]}\end{array}$ & $\begin{array}{l}16.0479 * * * \\
{[2.459]}\end{array}$ & $\begin{array}{c}17.4704^{* * *} \\
32\end{array}$ \\
\hline 2nd tercile, school's PSU 475-525 & $\begin{array}{c}-2.5411^{* *} \\
{[0.994]}\end{array}$ & $\begin{array}{c}-5.9283^{* * *} \\
{[0.812]} \\
493.29\end{array}$ & $\begin{array}{c}-4.1355^{* * *} \\
{[0.836]}\end{array}$ & $\begin{array}{r}-1.6428 \\
{[2.437]} \\
489\end{array}$ & $\begin{array}{r}0.1564 \\
15\end{array}$ \\
\hline 3rd tercile, school's PSU $475-525$ & $\begin{array}{c}-11.5236^{* * *} \\
{[1.013]}\end{array}$ & $\begin{array}{c}-17.9527^{* * *} \\
{[0.900]} \\
484.84\end{array}$ & $\begin{array}{c}-13.7773^{* * *} \\
{[0.891]}\end{array}$ & $\begin{array}{c}-10.9403^{* * *} \\
{[2.438]} \\
479\end{array}$ & $\begin{array}{c}-6.7172^{* * *} \\
{[2.204]} \\
61\end{array}$ \\
\hline 2nd tercile, school's PSU > 525 & $\begin{array}{c}-4.7199^{* * *} \\
{[0.504]}\end{array}$ & $\begin{array}{c}-6.5427^{* * *} \\
{[0.539]} \\
575.58\end{array}$ & $\begin{array}{c}-6.4042^{* * *} \\
{[0.530]}\end{array}$ & $\begin{array}{c}-10.1185^{* * *} \\
{[2.414]}\end{array}$ & $\begin{array}{c}-10.4580^{* * *} \\
{[2.160]} \\
48\end{array}$ \\
\hline 3rd tercile, school's PSU $>525$ & $\begin{array}{c}-14.5468^{* * *} \\
{[0.616]}\end{array}$ & $\begin{array}{c}-19.4922^{* * *} \\
{[0.862]} \\
566.75\end{array}$ & $\begin{array}{c}-17.6407^{* * *} \\
{[0.823]}\end{array}$ & $\begin{array}{c}-24.1491^{* * *} \\
\quad[2.531] \\
525\end{array}$ & $\begin{array}{c}-22.7199^{* * * *} \\
\quad[2.268] \\
53\end{array}$ \\
\hline Observations & $5,257,456$ & $5,257,503$ & $5,257,503$ & $3,161,920$ & $3,161,920$ \\
\hline R-squared & 0.748 & 0.893 & 0.897 & 0.749 & 0.766 \\
\hline Individual Controls & $\mathrm{X}$ & $\mathrm{X}$ & $\mathrm{X}$ & $\mathrm{X}$ & $\mathrm{X}$ \\
\hline $\begin{array}{l}\text { Year FE } \\
\text { School FF }\end{array}$ & $\mathrm{X}$ & $\mathrm{X}$ & $\mathrm{X}$ & $\mathrm{X}$ & $\begin{array}{l}X \\
X\end{array}$ \\
\hline $\begin{array}{l}\text { School FE } \\
\text { Municipality FE }\end{array}$ & & $\mathrm{X}$ & $\mathrm{x}$ & & $\mathrm{X}$ \\
\hline Individual $\mathrm{FE}$ & & $\mathrm{X}$ & $\mathrm{X}$ & $\mathrm{X}$ & \\
\hline Municipality-Year Interactions & & & $\mathrm{X}$ & & $\mathrm{X}$ \\
\hline
\end{tabular}


Table 11: Fail to pass grade by (estimated) school's PSU and ranking in 6th grade

\begin{tabular}{|c|c|c|c|c|c|}
\hline \multirow[t]{2}{*}{ VARIABLES } & \multicolumn{3}{|c|}{ All Schools } & \multicolumn{2}{|c|}{ Only primary } \\
\hline & $(1)$ & $(2)$ & (3) & (4) & (5) \\
\hline \multirow[t]{2}{*}{ 1st tercile, school's PSU $<425$} & $\begin{array}{c}-0.0155^{* * *} \\
{[0.001]}\end{array}$ & $\begin{array}{c}-0.0311 \text { *** } \\
{[0.002]}\end{array}$ & $\begin{array}{c}-0.0520^{* * * *} \\
{[0.003]}\end{array}$ & $\begin{array}{c}-0.0223 * * * \\
{[0.004]}\end{array}$ & $\begin{array}{c}-0.0414^{* * *} \\
{[0.005]}\end{array}$ \\
\hline & & 0.018 & & \multicolumn{2}{|c|}{0.020} \\
\hline \multirow[t]{2}{*}{ 2nd tercile, school's PSU $<425$} & $\begin{array}{c}0.0262^{* * *} \\
{[0.001]}\end{array}$ & $\begin{array}{c}0.0386^{* * *} \\
{[0.002]}\end{array}$ & $\begin{array}{c}0.0389^{* * * *} \\
{[0.003]}\end{array}$ & $\begin{array}{c}0.0532^{* * *} \\
{[0.005]}\end{array}$ & $\begin{array}{c}0.0575^{* * *} \\
{[0.005]}\end{array}$ \\
\hline & & 0.062 & & \multicolumn{2}{|c|}{0.062} \\
\hline \multirow[t]{2}{*}{ 3rd tercile, school's PSU $<425$} & $\begin{array}{c}-0.0031 \\
{[0.002]}\end{array}$ & $\begin{array}{l}0.0023 \\
{[0.003]}\end{array}$ & $\begin{array}{c}0.1041^{* * *} \\
{[0.003]}\end{array}$ & $\begin{array}{c}0.0141^{* *} \\
{[0.006]}\end{array}$ & $\begin{array}{c}0.1206^{* * *} \\
{[0.005]}\end{array}$ \\
\hline & & 0.177 & & \multicolumn{2}{|c|}{0.177} \\
\hline 1st tercile, school's PSU $425-475$ & $\begin{array}{c}-0.0120^{* * *} \\
{[0.001]}\end{array}$ & $\begin{array}{c}-0.0219^{* * *} \\
{[0.003]} \\
0.011\end{array}$ & $\begin{array}{c}-0.0349^{* * *} \\
{[0.003]}\end{array}$ & $\begin{array}{c}-0.0331^{* * *} \\
{[0.004]}\end{array}$ & $\begin{array}{l}-0.0622^{* * *} \\
{[11}\end{array}$ \\
\hline 2nd tercile, school's PSU 425-475 & $\begin{array}{c}0.0230^{* * *} \\
{[0.002]}\end{array}$ & $\begin{array}{c}0.0330^{* * *} \\
{[0.003]} \\
0.041\end{array}$ & $\begin{array}{c}0.0323 * * * \\
{[0.003]}\end{array}$ & $\begin{array}{c}0.0371^{* * *} \\
{[0.005]}\end{array}$ & ${ }^{0.0275^{* * *}}[0.005]$ \\
\hline 3rd tercile, school's PSU 425-475 & $\begin{array}{c}0.0142^{* * *} \\
{[0.002]}\end{array}$ & $\begin{array}{c}0.0212^{* * *} \\
{[0.004]} \\
0.146\end{array}$ & $\begin{array}{c}0.1063^{* * *} \\
{[0.004]}\end{array}$ & $\begin{array}{l}0.0022 \\
{[0.006]}\end{array}$ & ${ }^{[0.006]}$ \\
\hline 1st tercile, school's PSU $475-525$ & $\begin{array}{c}-0.0049^{* * *} \\
{[0.002]}\end{array}$ & $\begin{array}{c}-0.0068^{* *} \\
{[0.003]} \\
0.006\end{array}$ & $\begin{array}{c}-0.0182^{* * *} \\
{[0.003]}\end{array}$ & $\begin{array}{c}-0.0183^{* * *} \\
{[0.005]}\end{array}$ & $0.0 .0326^{* * *}$ \\
\hline 2nd tercile, school's PSU 475-525 & $\begin{array}{c}0.0205^{* * *} \\
{[0.002]}\end{array}$ & $\begin{array}{c}0.0280^{* * *} \\
{[0.003]} \\
0.024\end{array}$ & $\begin{array}{c}0.0254^{* * *} \\
{[0.003]}\end{array}$ & $\begin{array}{c}0.0406^{* * *} \\
{[0.005]}\end{array}$ & ${ }_{25}^{0.0372^{* * *}}$ \\
\hline 3rd tercile, school's PSU 475-525 & $\begin{array}{c}0.0219^{* * *} \\
{[0.003]}\end{array}$ & $\begin{array}{c}0.0218^{* * *} \\
{[0.005]} \\
0.117\end{array}$ & $\begin{array}{c}0.1002^{* * *} \\
{[0.004]}\end{array}$ & $\begin{array}{c}0.0275 * * * \\
{[0.006]}\end{array}$ & ${ }^{0.1056^{* * *}}[0.005]$ \\
\hline 2nd tercile, school's PSU > 525 & $\begin{array}{c}0.0123^{* * *} \\
{[0.001]}\end{array}$ & $\begin{array}{c}0.0178^{* * *} \\
{[0.001]} \\
0.011\end{array}$ & $\begin{array}{c}0.0227^{* * *} \\
{[0.002]}\end{array}$ & $\begin{array}{c}0.0340^{* * *} \\
{[0.003]}\end{array}$ & $19^{\left[0.0048^{* * *}\right.}$ \\
\hline 3rd tercile, school's PSU $>525$ & $\begin{array}{c}0.0228^{* * *} \\
{[0.002]}\end{array}$ & $\begin{array}{c}0.0314^{* * *} \\
{[0.004]} \\
0.080\end{array}$ & $\begin{array}{c}0.0904^{* * *} \\
{[0.004]}\end{array}$ & $\begin{array}{c}0.0320 * * * \\
{[0.007]}\end{array}$ & $0.0972^{* * *}$ \\
\hline Observations & $5,297,488$ & $5,297,535$ & $5,297,535$ & $3,189,750$ & $3,189,750$ \\
\hline R-squared & 0.084 & 0.341 & 0.458 & 0.345 & 0.459 \\
\hline Individual Controls & $\mathrm{X}$ & $\mathrm{X}$ & $\mathrm{X}$ & $\mathrm{X}$ & $\mathrm{X}$ \\
\hline Year FE & $\mathrm{X}$ & $\mathrm{X}$ & $\mathrm{X}$ & $\mathrm{X}$ & $\mathrm{X}$ \\
\hline Individual FE & & $\mathrm{X}$ & $\mathrm{X}$ & $\mathrm{X}$ & \\
\hline Municipality FE & & $\mathrm{X}$ & $\mathrm{X}$ & & $\mathrm{X}$ \\
\hline Municipality-Year Interactions & & & $\mathrm{X}$ & & $\mathrm{X}$ \\
\hline
\end{tabular}

Robust standard errors in brackets clustered by school. ${ }^{* * *} \mathrm{p}<0.01,{ }^{* *} \mathrm{p}<0.05,{ }^{*} \mathrm{p}<0.1$. Sample means in italics 
Table 12: Results for women age 15-19. CASEN survey 1990-2011

\begin{tabular}{|c|c|c|c|c|c|c|}
\hline \multirow[b]{2}{*}{ VARIABLES } & \multicolumn{3}{|c|}{ Dropout } & \multicolumn{3}{|c|}{ Teen Mom } \\
\hline & $(1)$ & $(2)$ & $(3)$ & $(4)$ & $(5)$ & $(6)$ \\
\hline Avg. PSU less than 425 in 2005 & $\begin{array}{c}-0.0495^{* *} \\
{[0.021]}\end{array}$ & $\begin{array}{c}-0.0459^{* *} \\
{[0.020]} \\
0.215\end{array}$ & $\begin{array}{c}-0.0450^{*} \\
{[0.026]}\end{array}$ & $\begin{array}{c}-0.0286^{* *} \\
{[0.012]}\end{array}$ & $\begin{array}{c}-0.0342^{* *} \\
{[0.013]} \\
0.085\end{array}$ & $\begin{array}{c}-0.0447^{* * *} \\
{[0.016]}\end{array}$ \\
\hline Avg. PSU $425-450$ in 2005 & $\begin{array}{c}-0.0642^{* * *} \\
{[0.021]}\end{array}$ & $\begin{array}{c}-0.0540^{* * *} \\
{[0.021]} \\
0.201\end{array}$ & $\begin{array}{c}-0.0343 \\
{[0.029]}\end{array}$ & $\begin{array}{c}-0.0261^{* *} \\
{[0.013]}\end{array}$ & $\begin{array}{c}-0.0319^{* *} \\
{[0.015]} \\
0.081\end{array}$ & $\begin{array}{c}-0.0461^{* *} \\
{[0.020]}\end{array}$ \\
\hline Avg. PSU 450-475 in 2005 & $\begin{array}{c}-0.0204 \\
{[0.022]}\end{array}$ & $\begin{array}{l}-0.0151 \\
{[0.024]} \\
0.195\end{array}$ & $\begin{array}{c}-0.0273 \\
{[0.027]}\end{array}$ & $\begin{array}{c}-0.0179 \\
{[0.012]}\end{array}$ & $\begin{array}{c}-0.0229 * \\
{[0.013]} \\
0.076\end{array}$ & $\begin{array}{c}-0.0403^{* *} \\
{[0.019]}\end{array}$ \\
\hline Avg. PSU 475-525 in 2005 & $\begin{array}{c}-0.0276 \\
{[0.019]}\end{array}$ & $\begin{array}{l}-0.0217 \\
{[0.019]} \\
0.175\end{array}$ & $\begin{array}{c}-0.0056 \\
{[0.020]}\end{array}$ & $\begin{array}{c}-0.0227^{*} \\
{[0.012]}\end{array}$ & $\begin{array}{c}-0.0256^{*} \\
{[0.013]} \\
0.067\end{array}$ & $\begin{array}{c}-0.0427^{* *} \\
{[0.017]}\end{array}$ \\
\hline Observations & 83,895 & 83,895 & 83,895 & 83,895 & 83,895 & 83,895 \\
\hline R-squared & 0.116 & 0.122 & 0.127 & 0.065 & 0.071 & 0.070 \\
\hline Individual Controls & $\mathrm{X}$ & $\mathrm{X}$ & $\mathrm{X}$ & $\mathrm{X}$ & $\mathrm{X}$ & $\mathrm{X}$ \\
\hline Year FE & $\mathrm{X}$ & $\mathrm{X}$ & $\mathrm{X}$ & $\mathrm{X}$ & $\mathrm{X}$ & $\mathrm{X}$ \\
\hline Municipality FE & & $\mathrm{X}$ & $\mathrm{X}$ & & $\mathrm{X}$ & $\mathrm{X}$ \\
\hline Municipality Linear Trends & & & $\mathrm{X}$ & & & $\mathrm{X}$ \\
\hline
\end{tabular}


Table 13: Fertility rates by municipality, 1994-2011

\begin{tabular}{|c|c|c|c|c|c|}
\hline VARIABLES & $\begin{array}{c}(1) \\
15-19\end{array}$ & $\begin{array}{c}(2) \\
20-24\end{array}$ & $\begin{array}{c}(3) \\
25-29\end{array}$ & $\begin{array}{c}(4) \\
30-34\end{array}$ & $\begin{array}{c}(5) \\
35-39\end{array}$ \\
\hline Avg. PSU less than 425 in 2005 & $\begin{array}{c}-0.0770^{* *} \\
{[0.036]} \\
96.51\end{array}$ & $\begin{array}{c}-0.0929^{* *} \\
{[0.039]} \\
149.62\end{array}$ & $\begin{array}{l}0.0321 \\
{[0.053]} \\
133.22\end{array}$ & $\begin{array}{l}-0.0918 \\
{[0.071]} \\
100.12\end{array}$ & $\begin{array}{c}-0.0724 \\
{[0.054]} \\
64.47\end{array}$ \\
\hline Avg. PSU $425-475$ in 2005 & $\begin{array}{c}-0.0658^{* *} \\
{[0.032]} \\
96.51\end{array}$ & $\begin{array}{c}-0.0934^{* * *} \\
{[0.033]} \\
148.69\end{array}$ & $\begin{array}{l}0.0659 \\
{[0.051]} \\
134.40\end{array}$ & $\begin{array}{l}-0.0486 \\
{[0.067]} \\
103.92\end{array}$ & $\begin{array}{c}-0.0489 \\
{[0.051]} \\
63.99\end{array}$ \\
\hline Avg. PSU $450-475$ in 2005 & $\begin{array}{c}-0.0496 \\
{[0.036]} \\
91.50\end{array}$ & $\begin{array}{c}-0.1062^{* * *} \\
{[0.033]} \\
147.10\end{array}$ & $\begin{array}{l}0.0160 \\
{[0.052]} \\
133.76\end{array}$ & $\begin{array}{l}-0.0930 \\
{[0.069]} \\
101.81\end{array}$ & $\begin{array}{c}-0.0749 \\
{[0.051]} \\
59.77\end{array}$ \\
\hline Avg. PSU $475-526$ in 2005 & $\begin{array}{c}-0.0737^{* *} \\
{[0.032]} \\
81.98\end{array}$ & $\begin{array}{c}-0.0945^{* * *} \\
{[0.035]} \\
140.46\end{array}$ & $\begin{array}{l}0.0084 \\
{[0.058]} \\
137.67\end{array}$ & $\begin{array}{l}-0.1127 \\
{[0.069]} \\
108.05\end{array}$ & $\begin{array}{c}-0.0843^{*} \\
{[0.049]} \\
62.95\end{array}$ \\
\hline $\begin{array}{l}\text { Observations } \\
\text { R-squared }\end{array}$ & $\begin{array}{l}5,047 \\
0.933\end{array}$ & $\begin{array}{l}5,052 \\
0.959\end{array}$ & $\begin{array}{l}5,052 \\
0.962\end{array}$ & $\begin{array}{l}5,050 \\
0.950\end{array}$ & $\begin{array}{l}5,041 \\
0.941\end{array}$ \\
\hline
\end{tabular}

